\title{
Eliminating Glutamatergic Input onto Horizontal Cells Changes the Dynamic Range and Receptive Field Organization of Mouse Retinal Ganglion Cells
}

\author{
(1)Sebastian Ströh, ${ }^{1,2}$ Christian Puller, ${ }^{3}$ (-Sebastian Swirski, ${ }^{1,4}$ Maj-Britt Hölzel, ${ }^{2}$ 느ea I.S. van der Linde, ${ }^{2}$ \\ 미asmin Segelken, ${ }^{1,3}$ Konrad Schultz, ${ }^{1}$ Christoph Block, ${ }^{3}$ Hannah Monyer, ${ }^{6}$ Klaus Willecke, ${ }^{7}$ Reto Weiler, ${ }^{1,5}$ \\ Martin Greschner, ${ }^{3,5}$-Ulrike Janssen-Bienhold, ${ }^{1,3,5}$ and ${ }^{-K a r i n}$ Dedek $^{1,2,5}$ \\ Departments of ${ }^{1}$ Neurobiology, ${ }^{2}$ Neurosensorics, ${ }^{3}$ Visual Neuroscience, ${ }^{4}$ Human Genetics, and ${ }^{5}$ Research Center Neurosensory Science, University of \\ Oldenburg, 26111 Oldenburg, Germany, ${ }^{6}$ German Cancer Research Center (DKFZ), 69120 Heidelberg, Germany, and ${ }^{7}$ Life and Medical Sciences Institute, \\ University of Bonn, 53115 Bonn, Germany
}

In the mammalian retina, horizontal cells receive glutamatergic inputs from many rod and cone photoreceptors and return feedback signals to them, thereby changing photoreceptor glutamate release in a light-dependent manner. Horizontal cells also provide feedforward signals to bipolar cells. It is unclear, however, how horizontal cell signals also affect the temporal, spatial, and contrast tuning in retinal output neurons, the ganglion cells. To study this, we generated a genetically modified mouse line in which we eliminated the light dependency of feedback by deleting glutamate receptors from mouse horizontal cells. This genetic modification allowed us to investigate the impact of horizontal cells on ganglion cell signaling independent of the actual mode of feedback in the outer retina and without pharmacological manipulation of signal transmission. In control and genetically modified mice (both sexes), we recorded the light responses of transient OFF- $\alpha$ retinal ganglion cells in the intact retina. Excitatory postsynaptic currents (EPSCs) were reduced and the cells were tuned to lower temporal frequencies and higher contrasts, presumably because photoreceptor output was attenuated. Moreover, receptive fields of recorded cells showed a significantly altered surround structure. Our data thus suggest that horizontal cells are responsible for adjusting the dynamic range of retinal ganglion cells and, together with amacrine cells, contribute to the center/surround organization of ganglion cell receptive fields in the mouse.

Key words: gain control; ganglion cells; glutamate receptor; horizontal cells; receptive field; retina

\section{Significance Statement}

Horizontal cells represent a major neuronal class in the mammalian retina and provide lateral feedback and feedforward signals to photoreceptors and bipolar cells, respectively. The mode of signal transmission remains controversial and, moreover, the contribution of horizontal cells to visual processing is still elusive. To address the question of how horizontal cells affect retinal output signals, we recorded the light responses of transient OFF- $\alpha$ retinal ganglion cells in a newly generated mouse line. In this mouse line, horizontal cell signals were no longer modulated by light. With light response recordings, we show that horizontal cells increase the dynamic range of retinal ganglion cells for contrast and temporal changes and contribute to the center/surround organization of their receptive fields.

\section{Introduction}

In the mammalian retina, ganglion cell responses are shaped by horizontal cells in the outer and amacrine cells in the inner retina.

Received Jan. 17, 2017; revised Dec. 20, 2017; accepted Jan. 2, 2018.

Author contributions: S. Ströh, C.P., R.W., M.G., U.J.-B., and K.D. designed research; S. Ströh, C.P., S. Swirski, M.-B.H., L.I.S.v.d.L., J.S., K.S., C.B., and K.D. performed research; H.M. and K.W. contributed unpublished reagents/ analytic tools; S. Ströh, C.P., S. Swirski, M.-B.H., L.I.S.v.d.L., J.S., K.S., C.B., M.G., and K.D. analyzed data; S. Ströh, C.P., and K.D. wrote the paper.

This work was supported by the Deutsche Forschungsgemeinschaft (Grant DE1154/3-1 to K.D. and U.J.-B.; RTG 1885/1 stipend to J.S.) and Volkswagen Stiftung (to M.G.). The funders had no role in study design, data collection and analysis, decision to publish, or preparation of the paper. We thank Peter Seeburg (deceased) from the University of Heidelberg for providing GluA2-floxed mice; Thomas Euler (University of Tübingen, Germany) for the chirp stimulus and the stimulation software QDS; Maxwell Turner (University of Washington, Seattle) for making available
Here we focus on the influence of horizontal cells on retinal output. Horizontal cells receive glutamatergic input from photoreceptors and mediate feedback signals to rods (Thoreson et al., 2008) and cones (Mangel, 1991; Wu, 1991; Jackman et al., 2011) and feedforward signals to bipolar cells (Yang and $\mathrm{Wu}, 1991$;

his MATLAB code for Gaussian fits, as well as Elahe Lotfi and Yousef Arzhangnia for help with MEA data processing; and Dr. Arndt Meyer (University of Oldenburg, Germany) for helpful discussions.

The authors declare no competing financial interests.

Correspondence should be addressed to Karin Dedek, Neurosensorics, Institute for Biology and Environmental Studies, University of Oldenburg, Carl-v.-Ossietzky-Straße 9-11, D-26111 Oldenburg, Germany. Email: karin.dedek@uni-oldenburg.de.

S. Ströh's present address: Princeton Neuroscience Institute, Princeton University, Princeton, NJ 08544.

DOI:10.1523/JNEUROSCI.0141-17.2018

Copyright $\odot 2018$ the authors $\quad 0270-6474 / 18 / 382015-14 \$ 15.00 / 0$ 
Fahey and Burkhardt, 2003). The mouse retina contains only one type of horizontal cell (Peichl and González-Soriano, 1994), which forms extensive networks coupled by gap junctions made of connexin57 (Janssen-Bienhold et al., 2009; Cx57) and connexin50 (Dorgau et al., 2015). Consequently, horizontal cells mediate spatially averaged signals to photoreceptors and are therefore thought to establish the antagonistic organization of receptive fields in all downstream neurons (Thoreson and Mangel, 2012), with center and surround responding with opposite polarity to light stimulation (Kuffler, 1953). However, in the mouse, amacrine cells also strongly contribute to the receptive field organization in ganglion cells (Taylor, 1999; Sinclair et al., 2004; Zaghloul et al., 2007; Marco et al., 2013).

Horizontal cell feedback changes the voltage dependence of calcium channels in the photoreceptor (Verweij et al., 1996; VanLeeuwen et al., 2009) and the strength of feedback is dependent on ambient light levels (Thoreson and Mangel, 2012). As neurotransmitter release is tightly linked to presynaptic calcium levels, horizontal cells are thought to regulate photoreceptor glutamate release in a light-dependent manner and keep the photoreceptor-bipolar cell synapse in its working range when light intensities change (Kamermans and Fahrenfort, 2004; Thoreson, 2007). By this gain control, horizontal cells may also indirectly influence the dynamic range of ganglion cells; some evidence for this effect has emerged recently (Chaya et al., 2017).

The nature of horizontal cell feedback to photoreceptors is controversial and may be different for different species (Thoreson and Mangel, 2012). Several mechanisms are discussed: ephaptic- (Kamermans et al., 2001), proton- (Hirasawa and Kaneko, 2003), or GABA-mediated feedback (Wu, 1992). A recent study indicates that all three mechanisms play a role in the mouse, with ephaptic feedback setting the basal calcium level, proton-mediated feedback affecting cone signals dependent on contrast and GABA modulating the two other feedback mechanisms (Kemmler et al., 2014). As all mechanisms involve different messengers, pharmacologically blocking horizontal cell feedback proved to be difficult (Dedek et al., 2008). Also, ablating horizontal cells failed to provide conclusive evidence because diphtheria toxin-induced ablation from mature retinas caused severe remodeling in the outer retina after 2-6 months (Sonntag et al., 2012), although tamoxifen-induced ablations may preserve the remaining circuitry for up to 2 weeks (Chaya et al., 2017).

To study horizontal cell function independent of potentially confounding pharmacology or structural changes, we used a novel approach. Mouse horizontal cells receive glutamatergic input from photoreceptors almost exclusively by AMPA receptors (Ströh et al., 2013), containing the subunits GluA2-4 (Hack et al., 2001). We deleted GluA4 from horizontal cells which reduced glutamate-induced currents by 75\% (Ströh et al., 2013). Based on subunit expression analysis, GluA2 appears to be the other major AMPA receptor subunit in horizontal cells (Hack et al., 2001). Hence, we additionally eliminated GluA2 and found that the residual glutamate-induced current was eliminated in GluA2/4-deficient horizontal cells. Thus, in this mouse line, horizontal cells were rendered insensitive to glutamate so that their feedback was presumably no longer light-dependent, no matter what the exact feedback mechanism is. We used this new mouse line to analyze the functional role of horizontal cells for ganglion cell tuning and compared light responses from transient OFF- $\alpha$ retinal ganglion cells (tOFF- $\alpha$ RGCs) in transgenic and control mice. We found that eliminating light-evoked input from photoreceptors to horizontal cells compressed the dynamic range of ganglion cells and strongly affected temporal, spatial and contrast tuning, likely because horizontal cell signaling to postsynaptic cells was no longer light-dependent and gain control at the photoreceptor synapse was impaired.

\section{Materials and Methods}

Animals and tissue preparation. All experiments were performed in accordance with the institutional guidelines for animal welfare and the laws on animal experimentation issued by the EU and the German government.

In GluA4fl/fl (Fuchs et al., 2007) and GluA2fl/fl mice (Shimshek et al., 2006), exon 11 of the GluA gene was flanked by loxP sites, which allows excision of the gene by Cre recombinase. Cre recombinase (Cre) was expressed under the $C x 57$ promoter. Mice not expressing Cre recombinase (GluA2fl/fl GluA4fl/fl:Cx57 ${ }^{+/+}$) served as controls and are designated as GluA2/4 fl/fl throughout the paper. To generate GluA-deficient mice, GluA2/4 fl/fl mice were crossed with Cx57+/Cre mice (Ströh et al., 2013); only mice that were homozygous for both floxed GluA alleles and hemizygous for the $C x 57$ allele (GluA2 fl/fl GluA4 fl/fl:Cx57+/Cre) were used for experiments. These mice are designated as GluA2/4 fl/fl:Cx $57+1$ Cre mice throughout the paper. Some control experiments were performed on GluA4 fl/fl:Cx57 ${ }^{+/+}$(designated as GluA4 fl/fl) and GluA4 fl/fl:Cx57+/Cre mice.

Mice [both sexes; ages: 2-4 months for patch- and whole-cell recordings, 3-9 months for multielectrode array (MEA) recordings, 3-6 months for immunohistochemistry] were anesthetized with $\mathrm{CO}_{2}$ (except for MEA recordings) and killed by cervical dislocation. For immunohistochemistry and ganglion cell recordings, eyes were enucleated and cornea, lens, and vitreous body were removed in carboxygenated $\left(95 \% \mathrm{O}_{2}\right.$, $5 \% \mathrm{CO}_{2}$ ) AMES medium (Sigma-Aldrich).

Immunohistochemistry. For immunohistochemistry on cryosections, eyecups were fixed in $2 \%$ paraformaldehyde in $0.1 \mathrm{~m}$ phosphate buffer (PB), $\mathrm{pH}$ 7.4, for 15-20 min. Immunostaining was performed as described previously (Ströh et al., 2013).

Primary antibodies for immunohistochemistry. The following primary antibodies were used in immunohistochemistry: monoclonal mouse anti-Cre recombinase (1:500; EUROMEDEX, CRE-2D8-AS; RRID: AB_2314230), polyclonal rabbit anti-calbindin (1:500; Swant, CB-38a; RRID:AB_10000340), monoclonal mouse anti-calbindin (1:1000; Swant, 300; RRID:AB_10000347), polyclonal rabbit anti-GluA2/3 (1:200; Millipore; RRID:AB_310741), polyclonal rabbit anti-GluA4 (1:500; Millipore; RRID:AB_90711), monoclonal mouse anti-GluK1 (1:150; Santa Cruz Biotechnology; RRID:AB_2716684), polyclonal goat anti-ChAT (1:100; Millipore; RRID:AB_2079751), monoclonal mouse anti-Cav1.1 (crossreacting with GPR179 in the retina; Hasan et al., 2016; 1:1000; Millipore; RRID: AB_2069582), and monoclonal mouse anti-bassoon (1:10,000; Enzo Life Sciences, SAP7F407; RRID:AB_2313990).

Electron microscopy. Electron microscopy was performed as described previously (Sonntag et al., 2012). Retinas were isolated from the eyecup and fixed in $1 \%$ paraformaldehyde with $3 \%$ sucrose and $2.5 \%$ glutaraldehyde in $\mathrm{PB}$ at $4^{\circ} \mathrm{C}$ overnight. After incubation in $1 \% \mathrm{OsO}_{4}$ in $\mathrm{PB}$ for $1 \mathrm{~h}$, several dehydration steps followed in $50-100 \%$ acetone. The tissue was finally embedded in resin (agar 100 resin, Plano) and tangential sections were cut and collected on copper grids. Images were taken with an EM902 Zeiss microscope.

Confocal microscopy and image analysis. To compare immunoreactivities, retina sections from the same experimental group were prepared and incubated on the same slide and scanned with a confocal microscope (Leica TCS SL or SP5) with identical settings. Image stacks were acquired with $40 \times($ NA 1.25 or 1.3 ) or $63 \times($ NA 1.32$)$ oil objectives. Images were adjusted in brightness and contrast for presentation purposes using Fiji (https://fiji.sc/; RRID:SCR_002285; Schindelin et al., 2012). Maximum projections of confocal stacks are shown.

Whole-cell recordings from dissociated horizontal cells. Dissociation of horizontal cells was performed as described earlier (Ströh et al., 2013). Briefly, retinas were isolated from the eyecups and dissociated enzymatically with papain $(20 \mathrm{U} / \mathrm{ml}$ in HBSS) in HBSS (Biochrom). The enzymatic reaction was stopped with DMEM, supplemented with DNase (100 $\mathrm{U} / \mathrm{ml}$ ) and fetal calf serum. The tissue was triturated using Pasteur pi- 
Table 1. Results from ANOVA on ranked data for frequency modulation (chirp stimulus) for GluA2/4 fl/fl versus GluA2/4 fl/fl:Cx57+/Cre mice (Fig. $5 b$ )

\begin{tabular}{|c|c|c|c|c|c|c|}
\hline \multicolumn{7}{|c|}{ Frequency modulation } \\
\hline \multirow[b]{2}{*}{ Spot diameter, $\mu \mathrm{m}$} & \multicolumn{2}{|c|}{ Effect of genotype } & \multicolumn{2}{|l|}{ Effect of frequency } & \multicolumn{2}{|l|}{ Interaction } \\
\hline & Fvalues & $p$ values & Fvalues & $p$ values & Fvalues & $p$ values \\
\hline 125 & $F_{(1,19)}=14.81$ & 0.0011 & $F_{(30,570)}=19.19$ & $<0.0001$ & $F_{(30,570)}=3.094$ & $<0.0001$ \\
\hline 300 & $F_{(1,19)}=27.08$ & $<0.0001$ & $F_{(30,570)}=38.95$ & $<0.0001$ & $F_{(30,570)}=4.295$ & $<0.0001$ \\
\hline 1000 & $F_{(1,19)}=22.69$ & 0.0001 & $F_{(30,570)}=34.39$ & $<0.0001$ & $F_{(30,570)}=1.794$ & 0.0064 \\
\hline
\end{tabular}

Table 2. Results from ANOVA on ranked data for contrast modulation (chirp stimulus) for GluA2/4 fl/fl versus GluA2/4 fl/fl:Cx57+/Cre mice (Fig. 5 c)

\begin{tabular}{|c|c|c|c|c|c|c|}
\hline \multicolumn{7}{|l|}{ Contrast modulation } \\
\hline \multirow[b]{2}{*}{ Spot diameter, $\mu \mathrm{m}$} & \multicolumn{2}{|c|}{ Effect of genotype } & \multicolumn{2}{|l|}{ Effect of contrast } & \multicolumn{2}{|l|}{ Interaction } \\
\hline & Fvalues & $p$ values & Fvalues & $p$ values & Fvalues & $p$ values \\
\hline 125 & $F_{(1,19)}=18.78$ & 0.0004 & $F_{(15,285)}=20.27$ & $<0.0001$ & $F_{(15,285)}=8.373$ & $<0.0001$ \\
\hline 300 & $F_{(1,19)}=33.05$ & $<0.0001$ & $F_{(15,285)}=44.81$ & $<0.0001$ & $F_{(15,285)}=6.914$ & $<0.0001$ \\
\hline 1000 & $F_{(1,19)}=37.00$ & $<0.0001$ & $F_{(15,285)}=46.95$ & $<0.0001$ & $F_{(15,285)}=6.156$ & $<0.0001$ \\
\hline
\end{tabular}

Table 3. Results from ANOVA on ranked data for frequency modulation (chirp stimulus) GluA4 fl/fl versus GluA4 fl/fl:Cx57+/Cre mice (Fig. 9)

\begin{tabular}{|c|c|c|c|c|c|c|}
\hline \multicolumn{7}{|c|}{ Frequency modulation } \\
\hline \multirow[b]{2}{*}{ Spot diameter, $\mu \mathrm{m}$} & \multicolumn{2}{|l|}{ Effect of genotype } & \multicolumn{2}{|l|}{ Effect of frequency } & \multicolumn{2}{|l|}{ Interaction } \\
\hline & Fvalues & $p$ values & Fvalues & $p$ values & $F$ values & $p$ values \\
\hline 125 & $F_{(1,11)}=0.04298$ & 0.8395 & $F_{(30,330)}=17.21$ & $<0.0001$ & $F_{(30,330)}=0.7775$ & 0.7950 \\
\hline 300 & $F_{(1,24)}=0.3386$ & 0.5661 & $F_{(30,720)}=44.96$ & $<0.0001$ & $F_{(30,720)}=1.247$ & 0.1721 \\
\hline 1000 & $F_{(1,24)}=0.3546$ & 0.5571 & $F_{(30,720)}=24.77$ & $<0.0001$ & $F_{(30,720)}=0.6912$ & 0.8929 \\
\hline
\end{tabular}

Table 4. Results from ANOVA on ranked data for contrast modulation (chirp stimulus) GluA4 fl/fl versus GluA4 fl/fl:Cx57+/Cre mice (Fig. 9)

\begin{tabular}{|c|c|c|c|c|c|c|}
\hline \multicolumn{7}{|l|}{ Contrast modulation } \\
\hline \multirow[b]{2}{*}{ Spot diameter, $\mu \mathrm{m}$} & \multicolumn{2}{|l|}{ Effect of genotype } & \multicolumn{2}{|l|}{ Effect of contrast } & \multicolumn{2}{|l|}{ Interaction } \\
\hline & $F$ values & $p$ values & $F$ values & $p$ values & Fvalues & $p$ values \\
\hline 125 & $F_{(1,11)}=0.1135$ & 0.7426 & $F_{(15,165)}=17.23$ & $<0.0001$ & $F_{(15,165)}=0.7233$ & 0.7585 \\
\hline 300 & $F_{(1,24)}=0.002239$ & 0.9627 & $F_{(15,360)}=67.93$ & $<0.0001$ & $F_{(15,360)}=0.2559$ & 0.9981 \\
\hline 1000 & $F_{(1,24)}^{(1,24)}=0.2083$ & 0.6522 & $F_{(15,360)}=48.36$ & $<0.0001$ & $F_{(15,360)}=0.9293$ & 0.5315 \\
\hline
\end{tabular}

pettes of decreasing open diameter. Retinal neurons were allowed to settle on glass coverslips coated with concanavalin A while incubating at $37^{\circ} \mathrm{C}$ in $5 \% \mathrm{CO}_{2}$ for at least $30 \mathrm{~min}$.

During recordings, coverslips were perfused with Ringer's solution containing the following (in mM): $137 \mathrm{NaCl}, 5.4 \mathrm{KCl}, 1.8 \mathrm{CaCl}_{2}, 1 \mathrm{MgCl}_{2}, 10$ D-glucose, 5 HEPES, pH 7.4. Horizontal cells were identified by their unique morphology (see Fig. 3c). Electrodes were made of borosilicate glass (3$6 \mathrm{M} \Omega$ resistance) and filled with intracellular solution, containing the following (in mM): $120 \mathrm{CsCl}, 1 \mathrm{CaCl}_{2}, 2 \mathrm{MgCl}_{2}, 20 \mathrm{TEA}-\mathrm{Cl}, 11$ EGTA, and 10 HEPES, pH 7.2. Currents were recorded with an EPC9 double patch-clamp amplifier at a sampling rate of $10 \mathrm{kHz}$. Glutamate solution was freshly prepared from stock solutions in Ringer's on each day (final concentration 1 $\mathrm{mm}$ ) and applied by an air pressure-driven application system (DAD-12 superfusion system, ALA Scientific). Data analysis was done with customwritten MATLAB scripts (R2016a, MathWorks; RRID:SCR_001622). Data were normalized to $10 \mathrm{pF}$ membrane capacitance.

Patch-clamp recordings from ganglion cells in retinal whole-mounts. Mice were dark-adapted for $1 \mathrm{~h}$ before kill. Retinas were dissected from the eyecup in dim red light in carboxygenated AMES medium. Several incisions were made to flatten the retina in the recording chamber. Electrodes were pulled from borosilicate glass and had resistances from 3 to $7 \mathrm{M} \Omega$ for cell-attached and 11-15 $\mathrm{M} \Omega$ for voltage-clamp recordings. For cell-attached recordings, electrodes were filled with carboxygenated AMES medium. During voltage-clamp experiments for conductance analysis, electrodes were filled with the following (in $\mathrm{mm}$ ): $100 \mathrm{CsOH}$, 100 gluconic acid, 10 Na-HEPES, 5 EGTA, 5 tetrabutylammonium-Cl, 5 Qx-314-Br, $3 \mathrm{Mg}$-ATP, $0.5 \mathrm{MgCl}_{2}, 0.5 \mathrm{CaCl}_{2}$, and 0.5 Na-GTP (pH 7.25) to block all voltage-gated conductances. Occasionally, $0.5-0.65 \%$ neurobiotin (RRID:AB_2313575) was added to the intracellular solution to visualize cell morphology (after incubation with streptavidinDyLight549; RRID:AB_2532067) and control for cell identity. Before recording, the retina was light-adapted in the setup for $10 \mathrm{~min}$. Then, a seal was established under infrared illumination of the microscope. Afterward, the patch of retina around the cell was light-adapted for another $10 \mathrm{~min}$ to reduce variability in adaptation state across experiments. Cells from dorsal and ventral retina were recorded and analyzed. Currents were amplified with an Axon CNS MultiClamp 700B amplifier, sampled, and filtered at 10 and $2.4 \mathrm{kHz}$, respectively.

Light stimulation for patch-clamp recordings. Light stimuli were delivered as described previously (Knop et al., 2011). Briefly, light stimuli were presented via a CRT monitor (HM 903 DT B; Iiyama; $60 \mathrm{~Hz}$ vertical refresh rate) using QDS 3.0.6 stimulation software (Euler et al., 2009) and focused onto the photoreceptors via the condenser of an upright microscope (Leica DM LFS). Monitor intensity was measured with an optometer (P-9710, Gigahertz-Optik). The photoisomerization $\left(\mathrm{P}^{\star}\right)$ rate was estimated by computing the inner product of the power-scaled emission spectra per unit area with the spectral sensitivity of the photoreceptors and multiplying the effective collecting area (M-cone: $0.37 \mu \mathrm{m}$, rod: $0.67 \mu \mathrm{m}$; Lyubarsky et al., 1999, 2004). This resulted in approximate rates of $2500 \mathrm{P}^{\star}$ per $\mathrm{M}$-cone per second and $4500 \mathrm{P}^{\star}$ per rod per second, which is well in the photopic range of mice (Dedek et al., 2008). Three types of light stimuli, centered on the soma of the recorded cell, were used: (1) a chirp stimulus consisting of a positive and negative contrast step followed by sinusoidal modulations of spot intensity $(I)$, first with increas- 
a

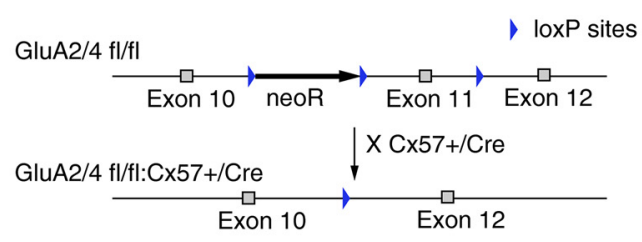

b

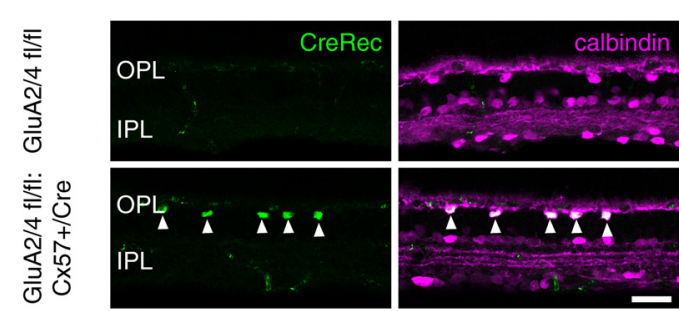

C

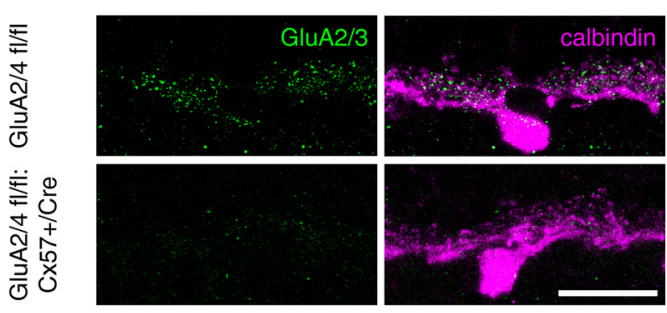

d

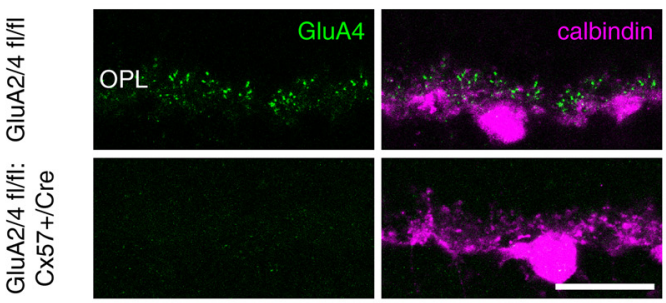

e

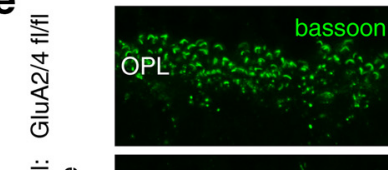

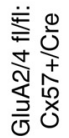

f
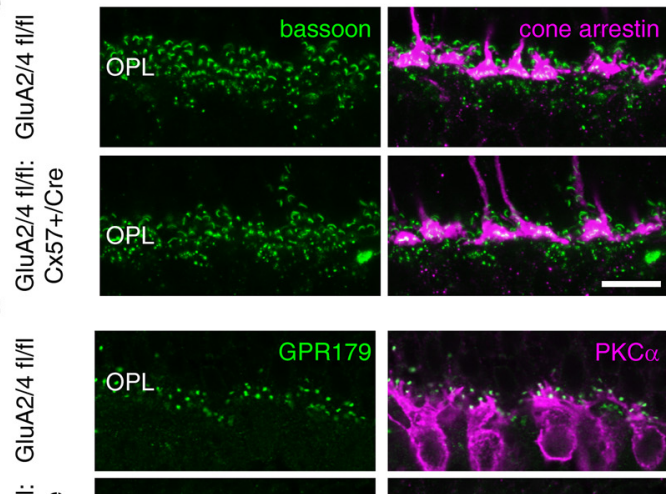

OPL
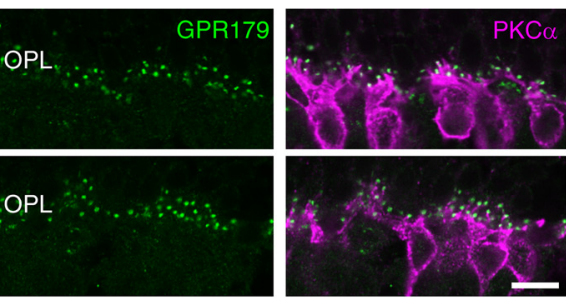

g
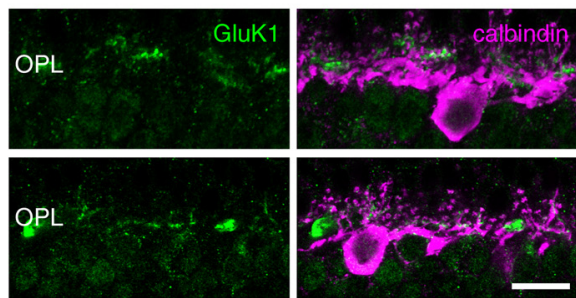

h
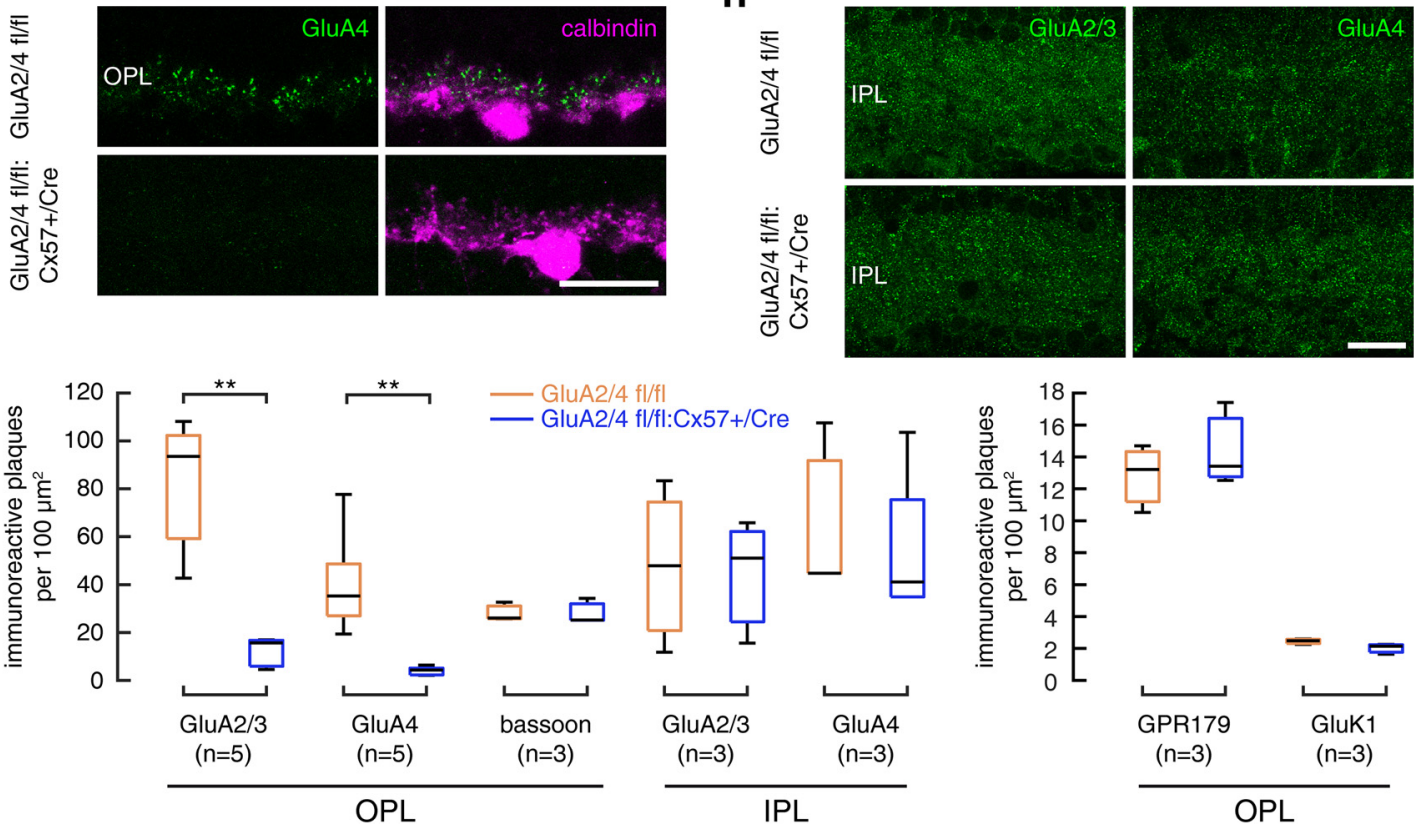

Figure 1. Targeted deletion of GluA2 and GluA4 in horizontal cells did not change outer retina morphology. $\boldsymbol{a}$, Targeting scheme. Exon 11 of the GluA2 and GluA4 genes was each flanked with loxP sites and deleted by crossing GluA2/4 fl/fl mice with Cx57+/Cre mice (Ströh et al., 2013). $\boldsymbol{b}$, Cre expression was restricted to horizontal cells, as revealed by double staining with the horizontal cell marker calbindin. $\boldsymbol{c}, \boldsymbol{d}$, In the outer retina of Cre-expressing mice, GluA2/3 (c) and GluA4 immunoreactivities ( $\boldsymbol{d}$ ) were reduced to background levels. $\boldsymbol{e}$, Cone pedicle morphology and bassoon labeling were normal in Cre-expressing mice. $\boldsymbol{f}$, Rod bipolar cell dendrites and GPR179 labeling, which reveals part of the mGluR6 signaling complex in 0N bipolar cells, were unchanged in Cre-expressing mice. $\boldsymbol{g}$, Labeling for kainic acid receptors (GluK1) was normal in Cre-expressing mice. $\boldsymbol{h}$, In the inner retina of (re-expressing mice, GluA2/3 and GluA4 immunoreactivities were unchanged. $\boldsymbol{i}$, Boxplots for the quantification of GluA2/3, GluA4, GluK1, GPR179, and bassoon immunoreactivity (IR) in the OPL and GluA2/3 and GluA4 immunoreactivity in the IPL. Quantification confirmed the expected reduction in GluA2/3- and GluA4-positive plaques in the outer retina of Cre-expressing mice (GluA2/4 fl/fl vs $+/$ Cre: Wilcoxon rank sum test, $p<0.01, n=5$ mice per genotype). The number of bassoon-labeled ribbon synapses, GluK1- and GPR179-positive plaques were unchanged compared with controls (GluA2/4 fl/fl vs $+/$ Cre: Wilcoxon rank sum test; bassoon: $p=0.7 ;$ GPR179: $p=0.8 ;$ GluK1: $p=0.2, n=3$ mice per genotype). Likewise, GluA2/3 and GluA4 immunoreactivities were unchanged in the IPL of Cre-expressing mice, confirming the specificity of the deletion (GluA2/4 fl/fl vs $+/$ Cre: Wilcoxon rank sum test, GluA2/3: $p=1 ;$ GluA4: $p=0.9, n=3$ mice per genotype). ${ }^{* *} p<0.01$. Scale bars, $20 \mu \mathrm{m}$. 
a

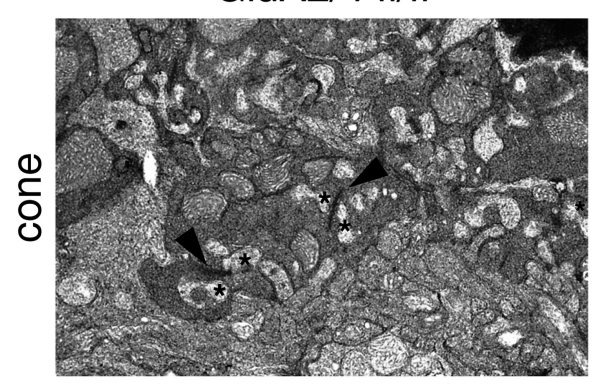

b

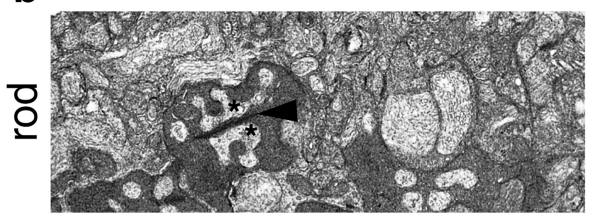

GluA2/4 fl/fl:Cx57+/Cre
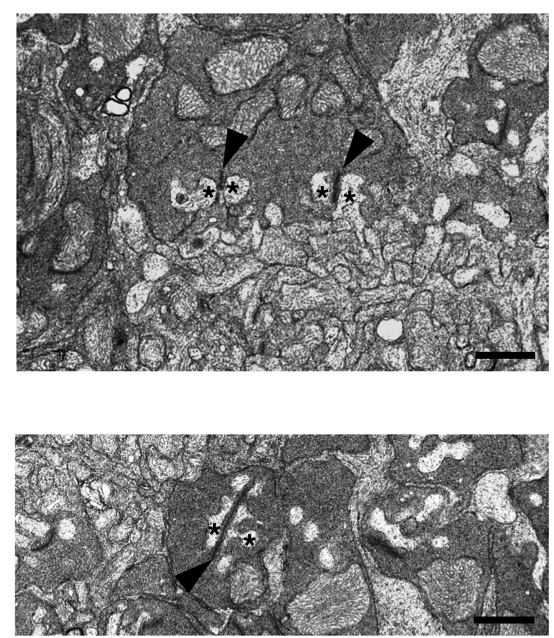

Figure 2. No evidence for alterations in triad synapses when GluA2 and GluA4 are deleted from horizontal cells. $\boldsymbol{a}, \boldsymbol{b}$, Representative electron micrographs from the outer plexiform layer of control and GluA2/4-deficient mice. Cone (a) and rod synapses (b) appeared unchanged in GluA2/4-deficient mice: two lateral horizontal cell processes (asterisks) flanked the synaptic ribbons (arrowheads), like in controls. Scale bar, $1 \mu \mathrm{m}$.

ing frequency $(0-8 \mathrm{~Hz})$ and then with increasing contrast (Baden et al., 2016); (2) drifting sine-wave gratings with 18 different, pseudorandomly interleaved spatial frequencies between 0.001 and 1.55 cycles/deg and a temporal frequency of $2 \mathrm{~Hz}$; and (3) 22 black spots of increasing diameter $(0-1250 \mu \mathrm{m})$ on gray background ( $-99 \%$ Michelson contrast) and a full-field stimulus whose area corresponded to a spot with $1900 \mu \mathrm{m}$ diameter. The chirp stimulus and drifting sine-wave gratings were presented on black and gray backgrounds, respectively, as circular areas with different diameters $(125,300$, and $1000 \mu \mathrm{m})$.

Data analysis of patch-clamp recordings from ganglion cells. Data analysis was performed with self-written scripts in MATLAB 2014 and 2016a. Current spikes were detected and spike rates were calculated using a bin size of $20 \mathrm{~ms}$. Spontaneous firing rates of tOFF- $\alpha$ RGCs were determined from responses to a white full-field stimulus (duration $10 \mathrm{~s}$ ). To find the highest stimulus frequency (starting at the lowest frequency) or lowest contrast (starting at the highest contrast) to which an individual cell responded, we defined a response threshold as mean spontaneous firing rate $+5 \times \mathrm{SD}$.

To estimate receptive field properties, responses $(R)$ to spots with increasing diameter $(2 \times r)$ were fit with a difference of Gaussians model, using lsqurvefit in MATLAB and the following equation:

$$
R=R_{0}+k c \times\left(1-e^{-\left(\frac{r}{2 \sigma c}\right)^{2}}\right)-k s \times\left(1-e^{-\left(\frac{r}{2 \sigma s}\right)^{2}}\right) .
$$

$R_{0}$ determines the vertical offset, the parameters $\sigma c$, and $\sigma$ s determine center and surround sizes, respectively. The parameters $k c$ and $k s$ determine center and surround weights, respectively. For each genotype, the model was fit to the mean normalized spike rate for all cells of one genotype.

Conductance analysis. The analysis is based on the assumption that the light-evoked synaptic currents contain an excitatory component [through nonselective cation ion channels with an equilibrium potential of $0 \mathrm{mV}\left(V_{\text {cat }}\right)$ ] and an inhibitory component [through ligand-gated chloride channels with a calculated chloride equilibrium potential of $-55 \mathrm{mV}\left(V_{\mathrm{Cl}}\right)$; Taylor and Vaney, 2002]. To make the two components visible, whole-cell recordings were performed with all voltage-gated channels blocked (for components of the intracellular solution see above). Before rupturing the membrane for whole-cell access, the ganglion cell type was determined with a $0.5 \mathrm{~s}$ white spot (diameter: 125,300 , and $1000 \mu \mathrm{m}$ ) on black background (interstimulus interval $9.5 \mathrm{~s}$, intensity: $2500 \mathrm{P}^{\star}$ per M-cone/s and $4500 \mathrm{P}^{\star}$ per rod/s). After establishing the whole-cell configuration, ganglion cells were clamped at holding potentials between -87 and $+42 \mathrm{mV}$ in $15 \mathrm{mV}$ steps and were stimulated for $0.5 \mathrm{~s}$ with a black spot on gray background of either 125,300 , or $1000 \mu \mathrm{m}$ diameter. The light stimulus started $2 \mathrm{~s}$ after the beginning of the voltage

step. For the analysis of current-voltage relations, holding potentials were corrected for the liquid junction potential $(-12.4 \mathrm{mV})$ and for errors introduced by the series resistance (Manookin et al., 2008). Current responses at each spot size were fit linearly over a voltage range of -87 to 12 $\mathrm{mV}$. From these fits, the reversal potential $\left(V_{\text {rev }}\right)$ and the excitatory and inhibitory conductances $\left(G_{\text {exc }}\right.$ and $\left.G_{\text {inh }}\right)$ were derived following established procedures (Taylor and Vaney, 2002; Manookin et al., 2008).

$M E A$ recordings. Retinas were recorded as described previously (Elstrott et al., 2008). Briefly, retinas were dissected from the eye-cup under infrared illumination. The dorsal half of the retina was mounted, ganglion cell side down, on a highdensity CMOS array (3Brain). During dissection and recording, the retina was perfused with AMES solution, pH 7.4 (Sigma-Aldrich) bubbled with carbogen $\left(95 \% \mathrm{O}_{2}\right.$ and $\left.5 \% \mathrm{CO}_{2}\right)$. Recordings were analyzed off-line to isolate the spikes of different cells, as described previously (Field et al., 2007). Candidate spike events were detected using a threshold on each electrode and the voltage waveforms on the electrode and neighboring electrodes around the time of the spike were extracted. Clusters of similar spike waveforms were identified as candidate neurons if they exhibited a refractory period. Duplicate recordings of the same cell were identified by temporal cross-correlation and removed.

RGCs were functionally classified into types based on their spatiotemporal receptive field properties, spike autocorrelation function and responses to full-field chirp stimulus (Baden et al., 2016). A dominant cell type in our data closely resembled tOFF- $\alpha$ RGCs. Further analysis was restricted to these functionally defined OFF- $\alpha$-like RGCs which for simplicity are called tOFF- $\alpha$ RGCs in the following (see Fig. $7 a-c$ ).

A monochrome pink noise stimulus with a natural spatio-temporal frequency fall-off (1/f) was used to characterize the response properties of recorded cells. The stimulus was presented on a CRT monitor at a refresh rate of $120 \mathrm{~Hz}$ and a pixel width of $41 \mu \mathrm{m}$ at an intensity of $\sim 31,000 \mathrm{P}^{\star}$ per $\mathrm{M}$-cone per second and $\sim 57,000 \mathrm{P}^{\star}$ per rod per second.

The receptive field was estimated as weight vector of a logistic regression model:

$$
q=\frac{1}{1+e^{\left(-w^{T} X-b\right)}}
$$

with receptive field filter $w$, bias term $b$, stimulus ensemble $X$, and the set of predictions $q$. The dimensionality of the stimulus ensemble was $32 \times$ 32 pixels and $333 \mathrm{~ms}$ for all selected spikes and three times the amount of non-spike events. The following loss function was minimized:

$$
L(p, q, w)=-\frac{1}{N} \sum_{i=1}^{N}\left[p_{i} \log q_{i}+\left(1-p_{i}\right) \log \left(1-q_{i}\right)\right]+\frac{\lambda}{2 N} \sum_{j=1}^{M} w_{j}^{2},
$$

with $p$ being the set of true labels of spike and non-spike events, $N$ the number of instances and $M$ the number of weights.

The spatial component of the receptive field filter was extracted over a time period of $33 \mathrm{~ms}$ before the peak. The spatial component was fitted with a difference of Gaussians model. In the control animals, the surround width was on average 2.3 (mean, 0.4 SD) larger than the center width. To constrain the fits, the surround width was fixed to 2.3 times the center width for all cells. For each cell, the ratio of center and surround amplitude was calculated. The fixed surround width did not influence the results because also the unrestricted fits showed a significantly weaker relative surround strength in cells from GluA2/4-deficient retinas $(p<$ 0.0001, Wilcoxon rank sum test). 
Experimental design and statistical analyses. Statistical analyses comprised parametric (where applicable) and nonparametric tests and are listed below for each data type. Data were checked for normality in MATLAB with the Kolmogoro$\mathrm{v}-$ Smirnov test. Outliers were always included in the statistical analysis. Throughout, we selected an $\alpha$ level of 0.05 . In boxplots, the central black line represents the median, the bottom and top boundaries of the box represent the lower and upper quartile, respectively. The whiskers extend to the largest and lowest values in the dataset, which are not outliers.

Immunohistochemistry data: densities of GluA2, GluA4, GluK1, GPR179, and bassoon stainings were quantified as described before (Ströh et al., 2013). Briefly, regions-of-interest were defined; thresholds were set manually and kept constant for the same experimental group. The number of immunoreactive puncta was averaged for each mouse (15-18 regions-ofinterest per animal, for each mouse only one retina was used for the staining). Values from three to five mice per genotype were compared with the Wilcoxon rank sum test (MannWhitney $U$ test) and presented as boxplots.

Patch-clamp recordings from dissociated horizontal cells: the size of inward currents was determined for both genotypes upon application of either Ringer's solution or glutamate. First, we tested within one genotype whether Ringer's and subsequent glutamate application differed, using a Wilcoxon signed rank test for paired data. Second, we tested whether the response to glutamate differed between genotypes, using a Wilcoxon rank sum test. Data are presented as boxplots.

Patch-clamp recordings from ganglion cells: a repeated-measures ANOVA was used to analyze the chirp data, with genotype and either contrast or frequency as factors. The entire dataset was ranked from smallest to largest before running the ANOVA (Conover and Iman, 1981); Sidak's post hoc test was used with correction for multiple comparisons (Prism6; GraphPad Software; RRID:SCR_002798). The factor frequency/contrast was always significant (for all spot sizes: $p<0.0001$ ); therefore, we only give $p$ values for the factor genotype in the Results text; the full statistics can be found in Tables 1-4. We also determined for each cell the highest frequency and lowest contrast, which elicited a response. These values were compared with Wilcoxon rank sum tests and presented as boxplots. To compare excitatory and inhibitory input across genotypes, conductances were integrated over the stimulus duration and presented as boxplots. A Wilcoxon rank sum test was used to test for statistical significance.

MEA recordings: data are presented as boxplots and were compared with a Wilcoxon rank sum test or a Wilcoxon signed rank test for a paired comparison.

\section{Results}

\section{Generation of a mouse line with GluA2/4-deficient horizontal cells}

To investigate the influence of horizontal cells on the light responses of ganglion cells, we generated genetically modified mice

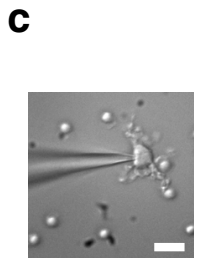

e
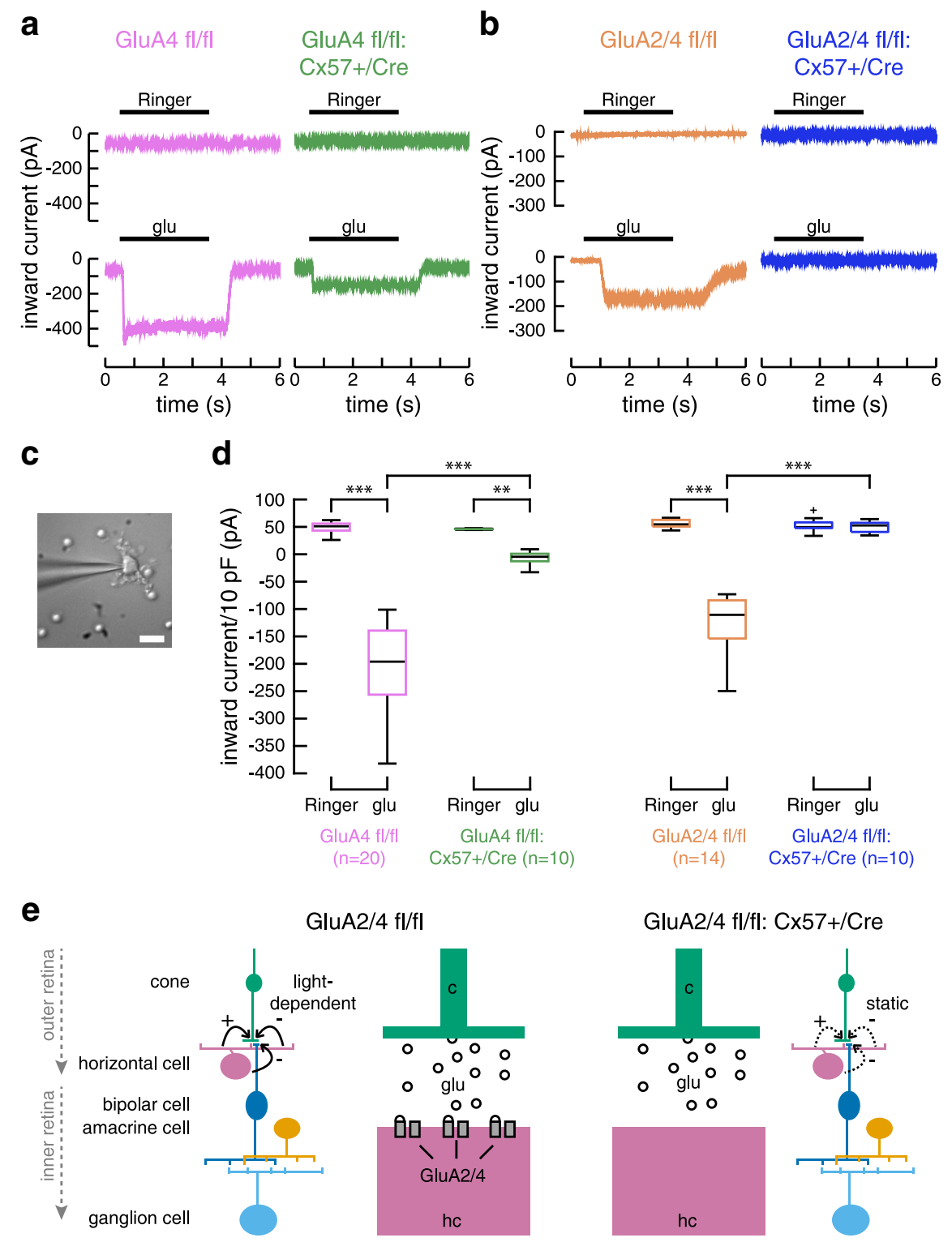

GluA2/4 fl/fl

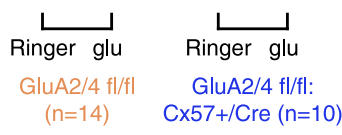

Figure 3. Targeted deletion of GluA2 and GluA4 in horizontal cells completely eliminated glutamate-induced inward currents. $\boldsymbol{a}$, When only GluA4 was deleted from horizontal cells, glutamate-induced currents were reduced but not abolished. Example traces for application of Ringer's solution and $1 \mathrm{~mm}$ glutamate (glu). Data replotted after Ströh et al., 2013. b, Deletion of both, GluA2 and GluA4, from horizontal cells eliminated glutamate-induced currents. Representative recordings with application of Ringer's solution and $1 \mathrm{~mm}$ glutamate. c, Dissociated horizontal cell with its typical morphology, targeted with a patch electrode. Scale bar, $10 \mu \mathrm{m}$. d, Boxplots of inward currents for control and GluA-deficient mice. Currents were normalized to $10 \mathrm{pF}$ of membrane capacitance to account for differences in cell size. The cross represents an outlier. Differences between genotypes were significant (glu application, GluA2/4 fl/fl vs +/Cre: Wilcoxon rank sum test, $p=4.7 \times 10^{-5}$ ). No difference was found between the application of Ringer's solution and $1 \mathrm{~mm}$ glutamate for GluA2/4-deficient mice ( $+/$ Cre, Ringer's vs glu: Wilcoxon sign rank test, $p=0.847) .{ }^{* *} p<0.01 ;{ }^{* * *} p<0.001$. $e$, Simplified diagram of the mammalian retina, showing the rationale of this study. Glutamate receptors are deleted from horizontal cells to deprive them from photoreceptor inputs. Please note that the strength of horizontal cell feedback (solid black arrows) is dependent on light intensity. Thus, depriving horizontal cells from photoreceptor inputs likely does not abolish feedback but eliminates its light-dependent modulation, leading to static feedback in GluA2/4deficient mice (dashed black arrows).

in which the AMPA receptor subunits GluA2 and GluA4 were deleted only in horizontal cells and in no other retinal cell type. We crossed mice that carried conditional alleles for GluA2 (Shimshek et al., 2006) and GluA4 (Fuchs et al., 2007; GluA2/4 $\mathrm{fl} / \mathrm{fl}$ ) with a mouse line in which one allele of $C x 57$ was replaced by the coding sequence of Cre recombinase (Ströh et al., 2013; GluA2/4 fl/fl:Cx57+/Cre; Fig. 1a). As the Cx57 promoter is only active in horizontal cells and a few cells in the thymus (Hombach 
a

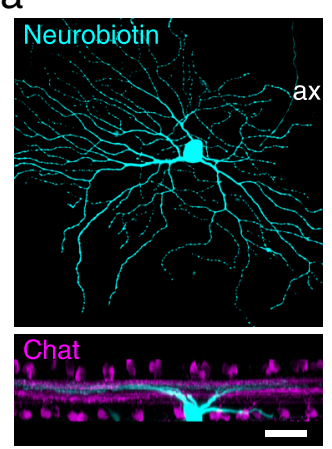

b
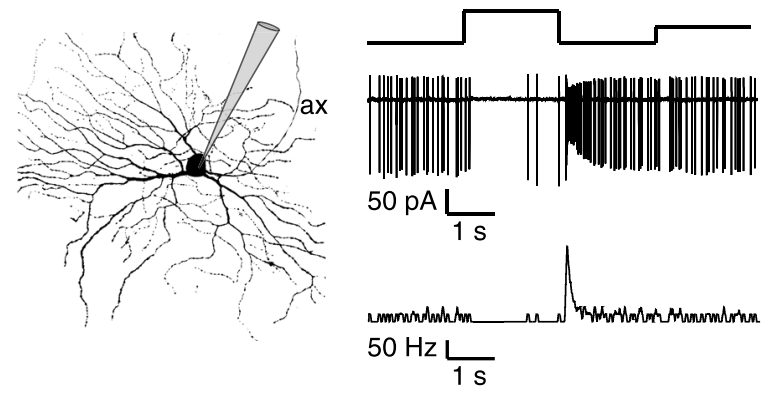

Figure 4. Targeted ganglion cells showed the characteristic morphology and light response of tOFF- $\alpha$ RGCs. $\boldsymbol{a}$, Neurobiotininjected ganglion cell, showing the characteristic morphology of tOFF- $\alpha \mathrm{RGCS}$ with a large soma and dendritic field. Scale bar, 40 $\mu \mathrm{m}$. ax, Axon. $\boldsymbol{b}$, Characteristic light response of a t0FF- $\alpha \mathrm{RGCS}$, showing only few spikes during light increment and a transient series of spikes at light decrement (Pang et al., 2003; Van Wyk et al., 2009; Baden et al., 2016; Krieger et al., 2017).

et al., 2004; Tykocinski et al., 2010; Ströh et al., 2013; Hirano et al., 2016), this led to cell-type-specific deletion of GluA2 and GluA4 in mouse horizontal cells. As a consequence, retina sections from GluA2/4 fl/fl:Cx57+/Cre mice showed immunoreactivity for Cre recombinase only in calbindin-labeled horizontal cells whereas retinas from GluA2/4 fl/fl mice (controls) were completely void of Cre-labeling (Fig. 1b).

We tested whether Cre expression indeed led to deletion of GluA2 and GluA4 from horizontal cells by labeling retinas for calbindin and GluA2/3 and GluA4. As expected, immunoreactivities for both glutamate receptor subunits were reduced to background levels in the outer plexiform layer (OPL) of Cre-expressing mice whereas controls showed strong GluA labeling close to calbindin-positive dendritic tips of horizontal cells (Fig. 1c,d). Quantification revealed differences between genotypes to be significant (Fig. $1 i ; p=0.0079$, Wilcoxon rank sum test). In contrast, GluA2/3 and GluA4 labeling in the inner plexiform layer (IPL) was unaffected (Fig. 1h, $i$; GluA2/3: $p=1$; GluA4: $p=0.9$, Wilcoxon rank sum test). In summary, our data show that we successfully deleted expression of GluA2 and GluA4 from horizontal cells.

\section{Morphology of retinas with GluA2/4-deficient horizontal cells is unaltered}

Depriving horizontal cells from their glutamatergic input may influence the formation of triad synapses where two horizontal cell processes and at least one $\mathrm{ON}$ bipolar cell dendrite invaginate photoreceptor terminals (Haverkamp et al., 2000). Hence, we analyzed electron micrographs from control and GluA2/4-deficient retinas and found no obvious differences in the morphology of triad synapses. In both genotypes, laterally invaginating horizontal cell processes (Fig. 2, asterisks) flanked ribbons in cone (Fig. 2a, arrowheads) and rod terminals (Fig. $2 b$, arrowheads). To confirm this finding, we also labeled retina sections of both genotypes for bassoon and cone arrestin (as markers for synaptic ribbons and cone photoreceptors, respectively). The staining appeared similar in both genotypes and counting all bassoon-positive plaques showed no differences between genotypes (Fig. $1 e ; p=0.7$, Wilcoxon rank sum test). To investigate the postsynaptic side of photoreceptor synapses, we also labeled for the mGluR6 signaling complex in ON bipolar cells with antibodies directed against Cav1.1, crossreacting with GPR179 (Hasan et al., 2016; Fig. 1f) and for GluK1 on OFF bipolar cells (Fig. 1 $g$ ). Again, we did not find any significant changes in the retinas of GluA2/4-deficient mice (Fig. 1i; GPR179: $p=0.8$; GluK1: $p=0.2$, Wilcoxon rank sum test). Thus, outer retina morphology was intact in mice that lacked GluA2 and GluA4 exclusively in horizontal cells.

\section{Glutamate-induced currents are abolished in GluA2/4-deficient horizontal cells}

To examine glutamate-induced currents in Cre-expressing mice, we performed patch-clamp recordings from dissociated horizontal cells (Fig. $3 a-d$ ). Although the majority of glutamate receptors is located on the dendritic processes and not on the soma of horizontal cells, such measurements can be used as a proxy for horizontal cells in situ because recent recordings of glutamate-induced currents in a horizontal slice preparation (Feigenspan and Babai, 2015) showed very similar results compared with measurements from dissociated horizontal cells (Ströh et al., 2013).

In horizontal cells from control mice, application of $1 \mathrm{~mm}$ glutamate led to inward currents of $\sim-200 \mathrm{pA}$ (normalized to 10 $\mathrm{pF}$ membrane capacitance to account for differences in the size of dissociated cells). When only the GluA4 subunit was deleted from horizontal cells, glutamate-induced currents were reduced by $\sim 75 \%$, as shown earlier (Ströh et al., 2013; Fig. 3a,d). When GluA2 and GluA4 were both deleted, glutamate application elicited no inward currents. Accordingly, responses to glutamate in GluA2/4-deficient horizontal cells were not distinguishable from responses to Ringer's solution (Fig. $3 b, d ; p=0.8457$, Wilcoxon sign rank test). In contrast, differences in the amplitude of glutamate-induced currents between control and GluA2/4deficient horizontal cells were significant $\left(p<4.71 \times 10^{-5}\right.$, Wilcoxon rank sum test). By deleting the two AMPA receptor subunits GluA2 and GluA4, we rendered horizontal cells insensitive to glutamatergic input from photoreceptors, a situation that should mimic the light-induced reduction of glutamate release from photoreceptors. As a consequence, the feedback of horizontal cells presumably is not modulated by light anymore, regardless of the nature of the feedback (Kemmler et al., 2014), because horizontal cells are clamped to "light-ON".

\section{The dynamic range of tOFF- $\alpha$ RGCs is compressed when horizontal cells lacked glutamatergic inputs}

Next, we used this mouse line to study the influence of horizontal cells on ganglion cell tuning and focused on tOFF- $\alpha$ RGCs. These ganglion cells are highly conserved in mammalian species (Peichl, 1991) and are rather uniformly distributed across the mouse retina (Bleckert et al., 2014). They can be easily identified based on their large cell body, the dendritic stratification right below the ChAT-immunoreactive band of OFF starburst amacrine cell dendrites in the OFF sublamina of the inner plexiform layer (Van Wyk et al., 2009; Fig. 4a), and their transient spike response to light decrements (Pang et al., 2003; Krieger et al., 2017; Fig. 4b). tOFF- $\alpha$ RGCs prefer large stimuli and high temporal frequencies and thus are well suited to study the role of horizontal cells in their tuning because horizontal cells were discussed to mediate rather broad surrounds (Zaghloul et al., 2007) and affect temporal tuning in ganglion cells (Dedek et al., 2008; Pandarinath et al., 2010).

To characterize the light response properties of tOFF$\alpha$ RGCs, we performed cell-attached recordings in the intact 
a

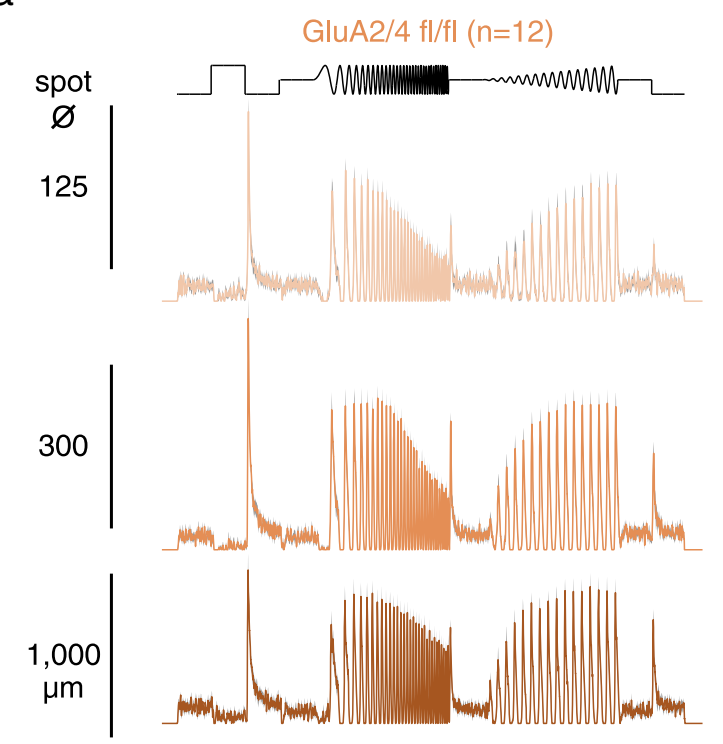

b
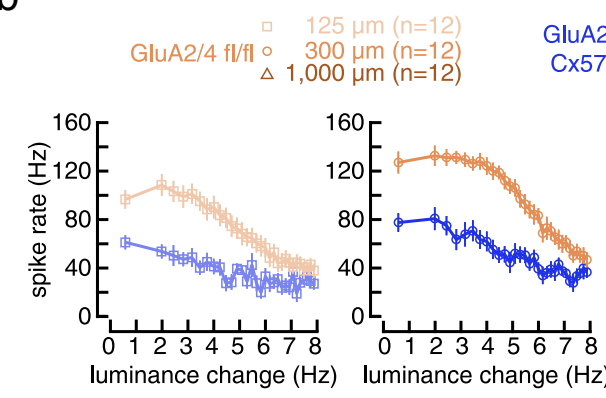

GluA2/4 fl/fl: $\square \quad 125 \mu \mathrm{m}(\mathrm{n}=9)$ Cx57+/Cre $\stackrel{\circ}{\triangle} \begin{gathered}300 \mu \mathrm{m} \\ \Delta 1,000 \mu \mathrm{m}(\mathrm{n}=9)\end{gathered}$

C
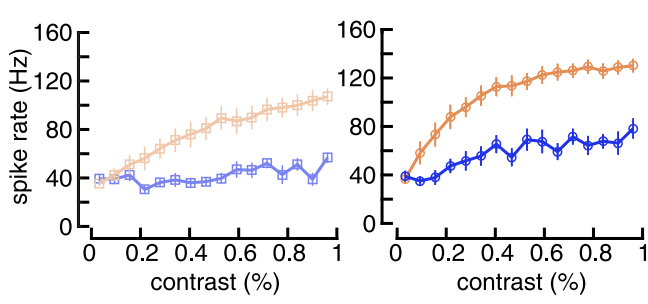
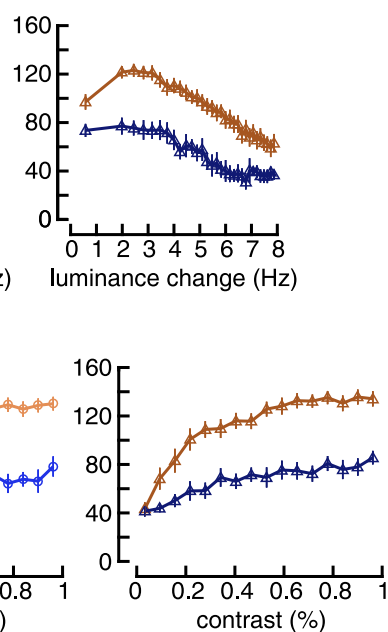

GluA2/4 fl/fl:Cx57+/Cre (n=9)
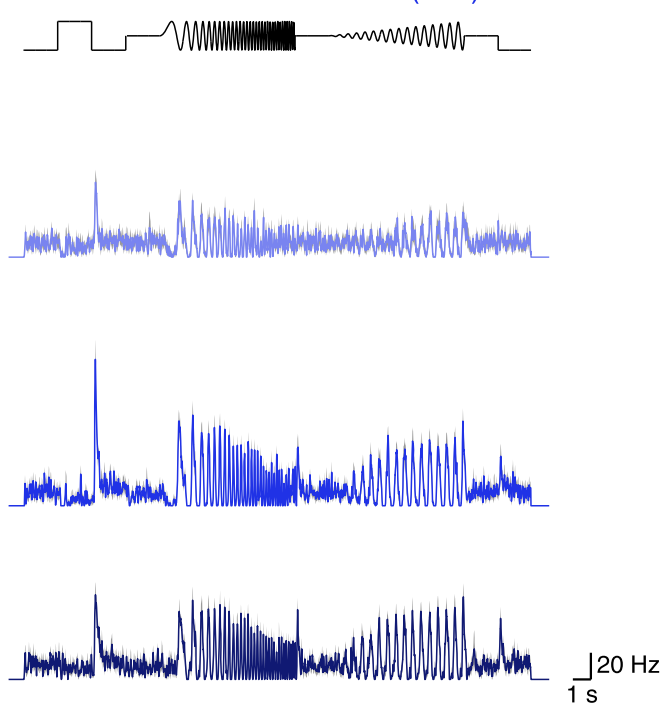

d

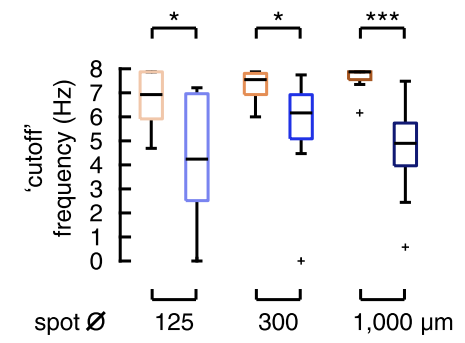

e

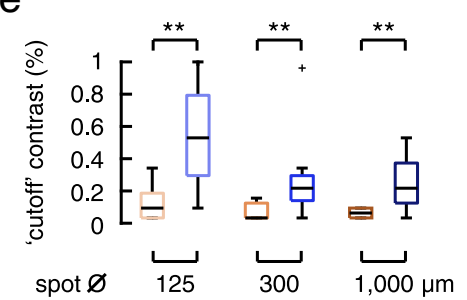

Figure 5. In GluA2/4-deficient mice, the dynamic range of light responses in tOFF- $\alpha \mathrm{RGC}$ was compressed. $\boldsymbol{a}$, Spike rates (bin size, $20 \mathrm{~ms}$ ) of t0FF- $\alpha \mathrm{RGCs}$ from control and GluA2/4-deficient mice to chirp stimuli of 125,300 , and $1000 \mu \mathrm{m}$ diameter. Values are shown as mean \pm SEM, with means presented as solid colored lines and SEM as gray shades. $\boldsymbol{b}, \boldsymbol{c}$, Peak spike rate plotted against temporal frequency $(\boldsymbol{b})$ or contrast $(\boldsymbol{c})$ for the two genotypes and all three spot sizes (values are presented as mean \pm SEM). Differences between genotypes were significant at all spot sizes (frequency: genotype effect: $p<0.0011$ for all comparisons; contrast: genotype effect: $p<0.0026$ for all comparisons; two-way ANOVA for repeated measures). $\boldsymbol{d}$, $\boldsymbol{e}$, "Cutoff" frequency (d) and contrast (e), i.e., the highest frequency and the lowest contrast that elicited a response (see Materials and Methods) were determined. Crosses represent outliers. Differences between genotypes were significant at all spot sizes (frequency: $p<0.02$ for all comparisons; contrast: $p<0.0086$ for all comparisons; Wilcoxon rank sum test), indicating that cells from GluA2/4-deficient mice failed to respond to high-frequency or low-contrast stimuli. ${ }^{*} p<0.05 ;{ }^{* *} p<0.01 ;{ }^{* * *} p<0.001$.

light-adapted whole-mount retina and compared temporal and contrast tuning between genotypes. Light stimuli were always centered at the soma of the recorded cell. To characterize response polarity, kinetics, as well as frequency and contrast tuning, we used a chirp stimulus, which was recently used to physiologically classify mouse ganglion cells (Baden et al., 2016). The stimulus was presented on black background in circular areas, either covering part of (125 $\mu \mathrm{m}$ diameter) or the entire receptive field center ( $300 \mu \mathrm{m}$ diameter) or covering the receptive field center and surround (1000 $\mu \mathrm{m}$ diameter). tOFF- $\alpha$ RGCs from controls (Fig. $5 a$, left) showed the typical response to light steps: almost no spikes during light increment and a transient burst of spikes in response to light decrement. Moreover, the cells were able to follow the chirp stimulus with increasing temporal frequency close to the highest frequency ( $8 \mathrm{~Hz}$; Fig. $5 a, b)$. Also, the cells responded with increasing spike rates to increasing contrasts (Fig. $5 a, c$ ). Overall, the spike responses of control cells looked very similar to the recently reported calcium responses and estimated spike rates of tOFF- $\alpha$ RGCs to the chirp stimulus (Baden et al., 2016).

In contrast, tOFF- $\alpha$ RGCs from retinas with GluA2/4deficient horizontal cells showed weak responses to the chirp stimulus with the smallest diameter (Fig. $5 a$, right). Moreover, for all stimulus sizes, spike rates were strongly attenuated compared with controls (Fig. $5 b, c$ ). These differences between genotypes were significant for the frequency and contrast chirp at all spot sizes (frequency: $125 \mu \mathrm{m}: p=0.0011 ; 300 \mu \mathrm{m}$ : 
a

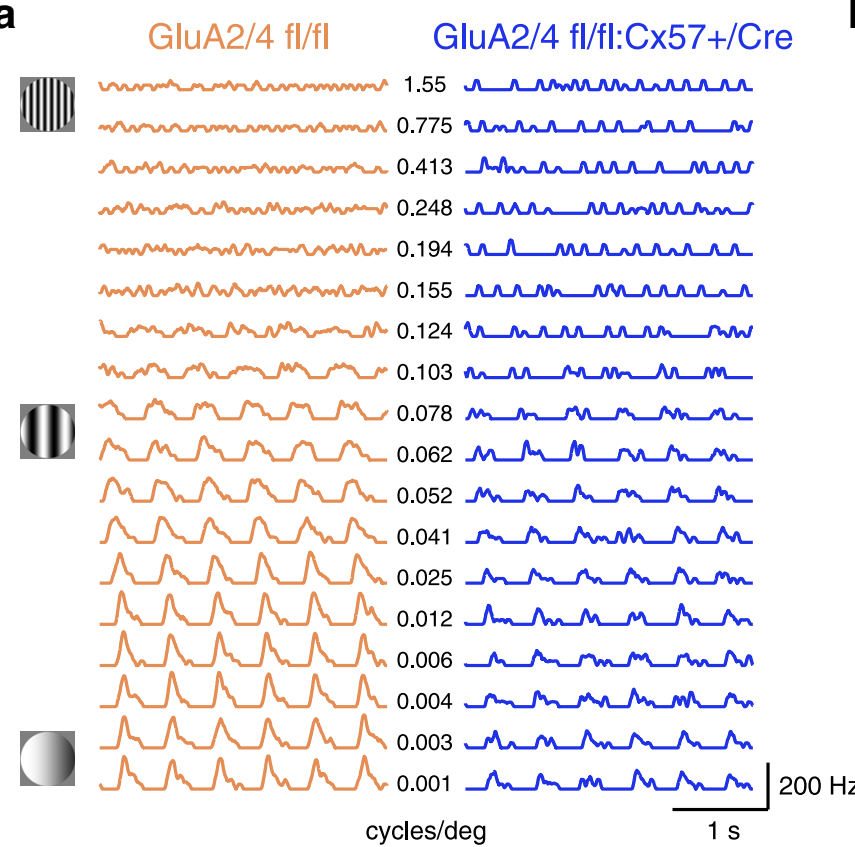

b
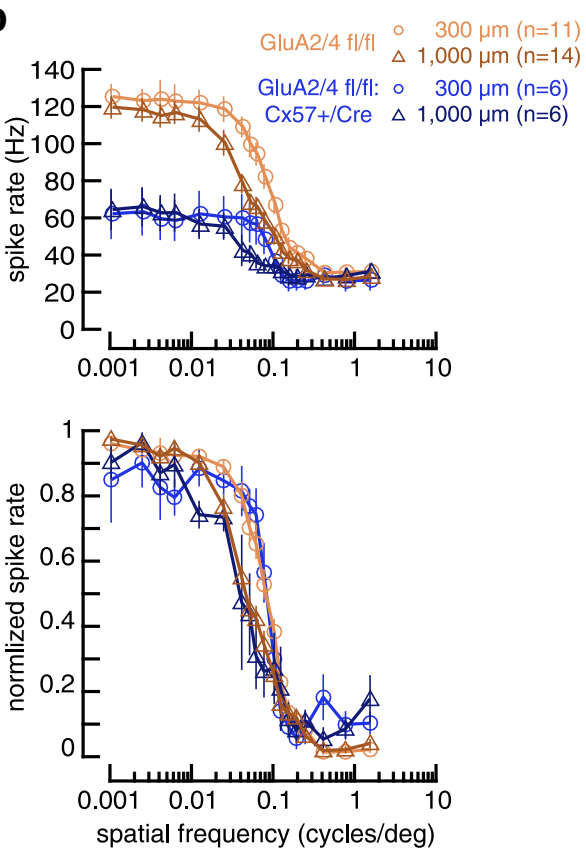

Figure 6. In GluA2/4-deficient mice, t0FF- $\alpha \mathrm{RGCS}$ showed reduced peak spike rates but no change in spatial tuning in response to drifting sine-wave gratings. $\boldsymbol{a}$, Representative responses of t0FF- $\alpha$ RGCs from control and GluA2/4-deficient mice to drifting sine-wave gratings (300 $\mu$ m diameter) with spatial frequencies ranging from 0.001 to 1.55 cycles/deg. $\boldsymbol{b}$, Peak spike rates plotted versus spatial frequency for two different stimulus diameters (300 and $1000 \mu \mathrm{m}$, top). tOFF- $\alpha \mathrm{RGCs}$ from GluA2/4-deficient mice showed much lower spike rates than controls. To compare responses independent of the absolute spike rate, we normalized spike rates to values between 0 and 1 . This revealed that spatial tuning showed a very similar dependence on spatial frequency and spot diameter in both genotypes: responses to the larger spot, which also covered part of the surround, fell off at lower spatial frequencies than for the small spot, which only covered the center of the receptive field. Values in $\boldsymbol{b}$ are shown as mean \pm SEM.

$p<0.0001 ; 1000 \mu \mathrm{m}: p=0.0001$; intensity: $125 \mu \mathrm{m}: p=0.0004$ $300 \mu \mathrm{m}: p<0.0001 ; 1000 \mu \mathrm{m}: p<0.0001$; repeated-measures ANOVA).

We also determined for each individual cell the highest frequency and lowest contrast that elicited a response and compared this between genotypes. Control cells were able to follow the chirp stimulus to significantly higher frequencies than cells from GluA2/4-deficient mice (mean \pm SEM; GluA2/4 fl/fl: $125 \mu \mathrm{m}$ : $6.8 \pm 0.3 \mathrm{~Hz} ; 300 \mu \mathrm{m}: 7.3 \pm 0.2 \mathrm{~Hz} ; 1000 \mu \mathrm{m}: 7.6 \pm 0.1 \mathrm{~Hz}$; GluA2/4 fl/fl:Cx57-Cre: $125 \mu \mathrm{m}: 4.3 \pm 0.9 \mathrm{~Hz} ; 300 \mu \mathrm{m}: 5.5 \pm$ $0.8 \mathrm{~Hz} ; 1000 \mu \mathrm{m}: 4.6 \pm 0.7 \mathrm{~Hz}$ ). This was true for all spot sizes (125 $\mu \mathrm{m}: p=0.02 ; 300 \mu \mathrm{m}: p=0.0114 ; 1000 \mu \mathrm{m}: p=0.0002$; Wilcoxon rank sum test). Similarly, control cells still responded to significantly weaker contrasts (mean \pm SEM; GluA2/4 fl/fl: 125 $\mu \mathrm{m}: 0.13 \pm 0.03 \% ; 300 \mu \mathrm{m}: 0.07 \pm 0.02 \% ; 1000 \mu \mathrm{m}: 0.06 \pm$ $0.01 \%$ ) than cells from GluA2/4-deficient mice (GluA2/4 fl/fl: Cx57-Cre: $125 \mu \mathrm{m}$ : $0.53 \pm 0.11 \% ; 300 \mu \mathrm{m}: 0.27 \pm 0.09 \%$; 1000 $\mu \mathrm{m}: 0.25 \pm 0.06 \% ; 125 \mu \mathrm{m}: p=0.0026 ; 300 \mu \mathrm{m}: p=0.0051$; $1000 \mu \mathrm{m}: p=0.0086$; Wilcoxon rank sum test). Thus, our results show that temporal (Fig. $5 b, d$ ) and contrast tuning (Fig. $5 c, e$ ) were strongly impaired in mice lacking glutamatergic input onto horizontal cells.

We also compared spontaneous firing rates in the same cells, determined during $10 \mathrm{~s}$ of steady full-field illumination and found no significant differences between genotypes (GluA2/4 fl/fl: $5 \pm 0.9$ spikes/s; GluA2/4 fl/fl:Cx57-Cre: $8.2 \pm 1.6 ; p=0.1452$ Wilcoxon rank sum test).

Thus, our results revealed that light responses of tOFF- $\alpha$ RGCs were compressed in their dynamic range and failed to respond to high temporal frequencies and low contrasts when horizontal cell feedback was not light-dependent anymore.
Impact of glutamate-insensitive horizontal cells on the receptive field structure/spatial tuning of tOFF- $\alpha$ RGCs Next, we probed spatial tuning in tOFF- $\alpha$ RGCs with drifting sine-wave gratings of different spatial frequencies. Stimuli were presented in circular areas either covering only the receptive field center (300 $\mu \mathrm{m}$ diameter) or center and surround (1000 $\mu \mathrm{m}$ diameter) of the cells. Spike rates were highest for low spatial frequencies and declined with increasing spatial frequency (Fig. $6 a, b)$. This was true for both genotypes. However, compared with controls, cells from GluA2/4-deficient mice again showed strongly reduced spike rates (Fig. $6 b$ ). Yet, when we normalized spike rates to values between 0 and 1 to compare response characteristics independent from the absolute spike rate, no differences were visible between genotypes: stimulation with larger gratings led to the same shift in spatial tuning toward lower spatial frequencies in both genotypes.

As horizontal cells modulate the signaling between photoreceptors and bipolar cells by lateral inhibition, horizontal cells are thought to contribute to the center/surround antagonism in bipolar cells, which is then forwarded to ganglion cells. We aimed to quantify the extent of horizontal cell contribution to surrounds in ganglion cells. However, grating stimuli did not elicit response suppression mediated by the receptive field surround in cells of either genotype, which would have been visible as a decrease in firing rate at low spatial frequencies. This is consistent with recent work on wild-type $\alpha$-ganglion cells by Krieger et al. (2017), and possibly due to stimulus features which were inappropriate to reveal surround effects in these cells. To test whether other stimuli fulfill this task more reliably, we first used a pink noise stimulus, which contained similar statistical properties as natural scenes, and simultaneously recorded spike responses 
a

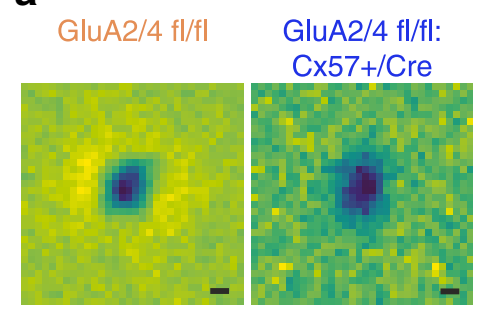

b

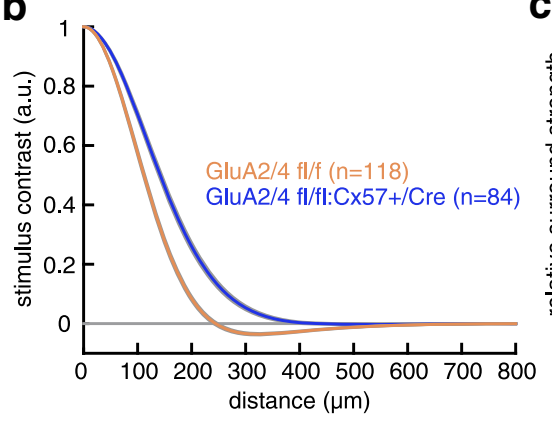

C

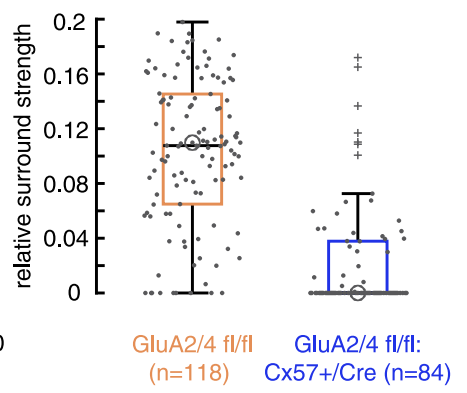

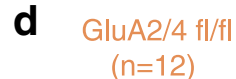

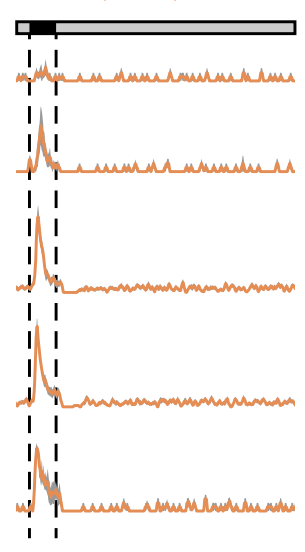

GluA2/4 fl/fl: Cx57+/Cre $(n=7)$

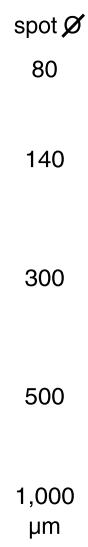

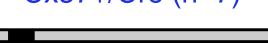

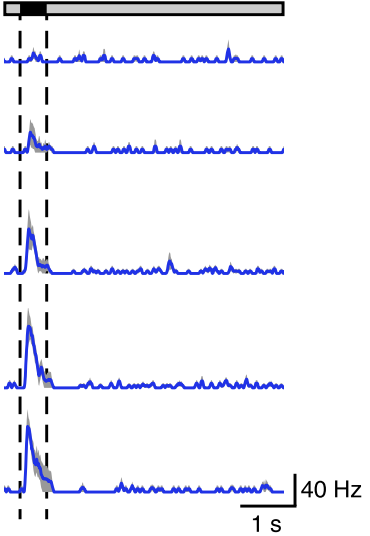

e

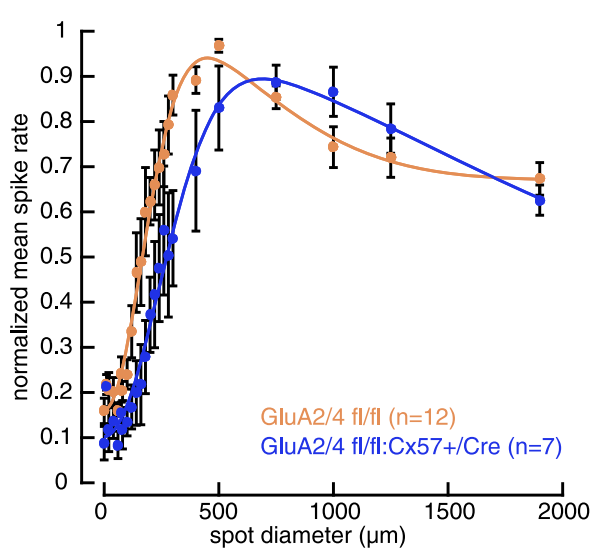

Figure 7. In GluA2/4-deficient mice, tOFF- $\alpha$ RGCs showed altered centers and surrounds. $\boldsymbol{a}$, Representative examples of spatial receptive fields of t0FF- $\alpha \mathrm{RGCS}$ from control and GluA2/4-deficient mice obtained by a logistic regression model (see Materials and Methods). The dark region, indicating a dominant OFF response, was surrounded by an aggregation of light regions in the control (left), indicating an antagonisticreceptive field surround, which is absent in the spatial receptive field of GluA2/4-deficient mice (right). Scale bar, $100 \mu \mathrm{m}$. $\boldsymbol{b}$, (ross-sectional profile of receptive fields for 118 control and 84 GluA2/4-deficient tOFF- $\alpha$ RGCS. Mean across difference of Gaussians fits is shown. Shaded area represents 1 SEM. $c$, Box plots showing the ratio of center and surround amplitude. Large points represent cells shown in $\boldsymbol{a}$. Crosses represent outliers. $\boldsymbol{d}$, Averaged spike rates (bin size $20 \mathrm{~ms}$ ) of tOFF- $\alpha$ RGCs from control and GluA2/4-deficient mice in response to selected spots of increasing diameter. Data are plotted as mean \pm SEM, with means presented as solid colored lines and SEM as gray shades. Dotted lines represent the stimulus. $\boldsymbol{e}$, Mean normalized spike rates were fit with a difference of two Gaussians model. Both genotypes showed the characteristic feature of antagonistic receptive field organization: increase in firing with increasing spots until a maximum was reached and a successive decline in firing rates with further increasing spot sizes. However, center and surround sizes were larger in GluA2/4-deficient mice. Also, the ratio of center/surround strength was larger in GluA2/4-expressing mice (2.3) than in GluA2/4-deficient mice (1.5). Fit parameters: GluA2/4 fl/fl: $R_{0}=0.16 ; k c=0.9 ; \sigma c=83 \mu \mathrm{m} ; \mathrm{ks}=0.39$; $\sigma s=295 \mu \mathrm{m} ; R^{2}=0.98 ;+/ C r e: R_{0}=0.1 ; k c=0.87 ; \sigma c=121 \mu \mathrm{m} ; k s=0.57 ; \sigma s=700 \mu \mathrm{m} ; R^{2}=0.98$. Values are shown as mean \pm SEM.

from many tOFF- $\alpha$ RGCs at once via a multielectrode array. We found that tOFF- $\alpha$ RGCs from control retinas showed a classical center-surround organization, whereas cells from GluA2/4deficient retinas largely lacked surrounds in these stimulus conditions (Fig. $7 a-c)$. Consequently, relative surround strength was significantly weaker in cells from GluA2/4-deficient retinas ( $p<$ 0.0001 , Wilcoxon rank sum test).

Given the known role of the inner retina in the surround formation (Taylor, 1999; Sinclair, 2004; Zaghloul et al., 2007; Marco et al., 2013; Franke et al., 2017), we presented black spots of increasing diameter to test the remaining surround during single-cell patch-clamp recordings (Fig. $7 d, e$ ). In controls, tOFF$\alpha$ RGCs showed the classical center/surround organization: peak firing rates increased with increasing spot diameter, reaching its peak at $\sim 400 \mu \mathrm{m}$. Larger spots led to decreased firing rates (by $\sim 40 \%$ ) as the surround of the cells was activated (Fig. 7e), consistent with a recent report (Krieger et al., 2017). For tOFF- $\alpha$ RGCs from GluA2/4-deficient mice, responses looked qualitatively similar (Fig. $7 e$ ). Peak firing rates increased up to a maximum and then decreased by $\sim 40 \%$. This indicates that even when horizontal cells were rendered insensitive to glutamate, surrounds could be elicited (Fig. $7 d, e$ ), which showed a greater spatial extent than in controls. More- over, peak firing rate reached its maximum at a larger spot size (750 $\mu \mathrm{m}$ ) compared with controls ( $400 \mu \mathrm{m} ; p=0.025$, Wilcoxon rank sum test).

In summary, GluA2/4-deficient mice show changes in receptive field organization: stimulation with weaker stimuli (pink noise) revealed an extensive reduction of surround strength in tOFF- $\alpha$ RGCs. Stimulation with large black spots on gray background, however, revealed altered surrounds in tOFF- $\alpha$ RGCs, which may reflect the contribution of amacrine cells (Taylor, 1999; Sinclair et al., 2004; Zaghloul et al., 2007; Marco et al., 2013; Franke et al., 2017; see Discussion).

\section{EPSCs in tOFF- $\alpha$ RGCs are strongly reduced when horizontal} cells were rendered insensitive to glutamate

If the sensitivity of the ganglion cells was indeed reduced, then ganglion cells received increased inhibitory input (from amacrine cells), decreased excitatory input (from bipolar cells), or both. To test this, we performed whole-cell recordings and compared the synaptic conductances between genotypes. Cells were clamped to various potentials and a black spot on gray background was presented for $500 \mathrm{~ms}$ during each voltage step (Fig. 
a

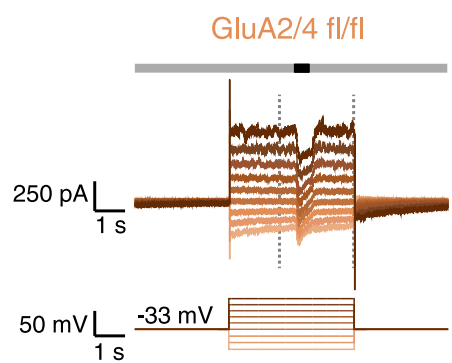

b
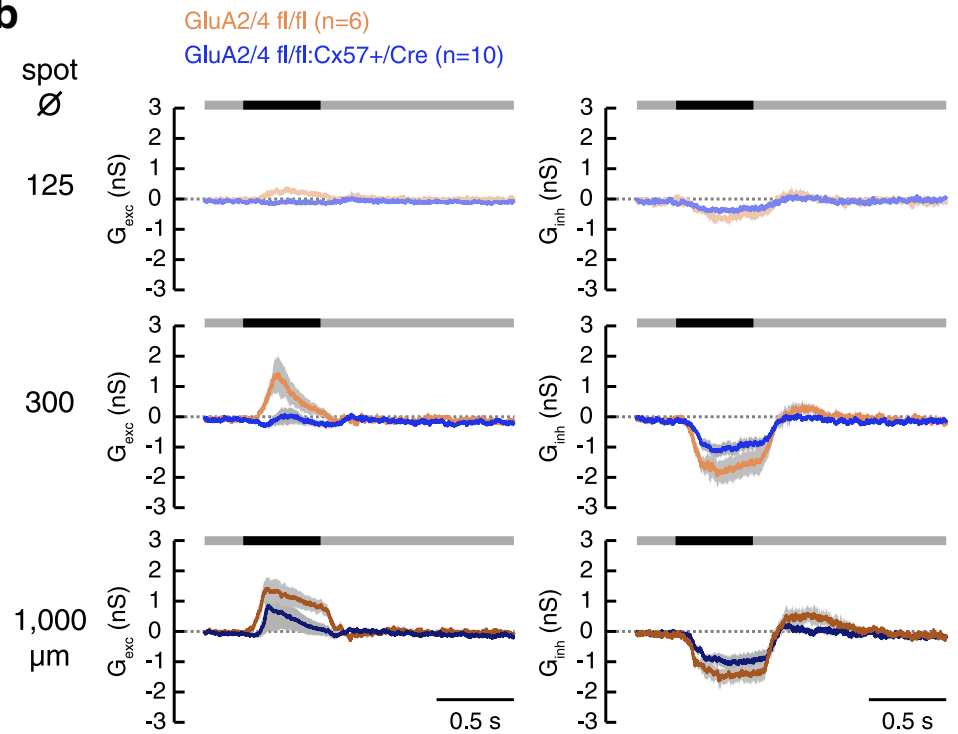

C
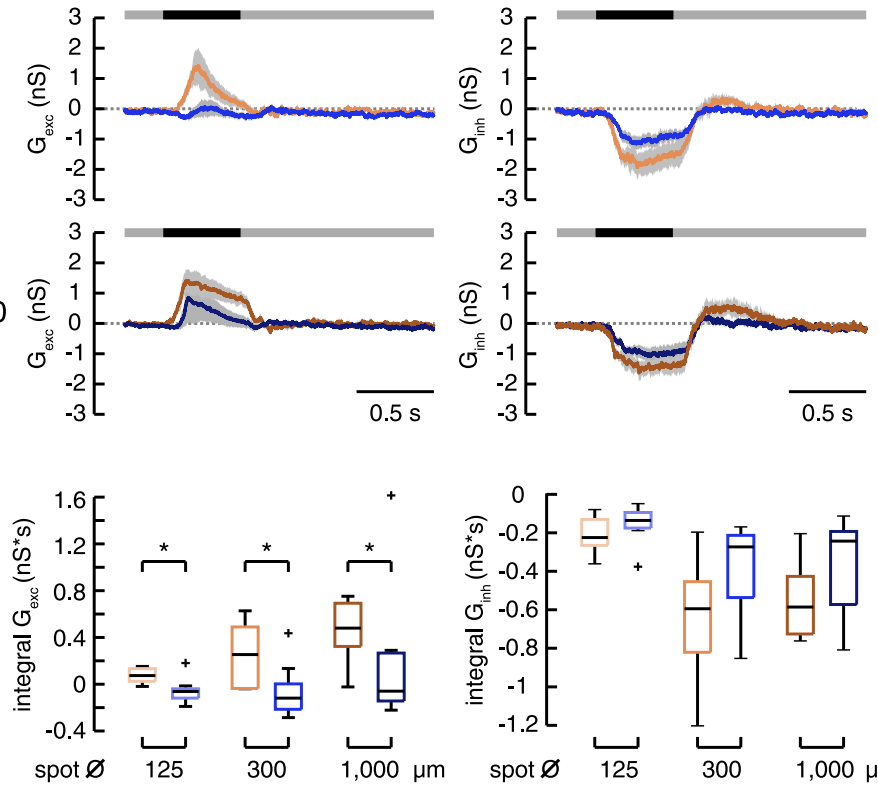

GluA2/4 fl/fl:Cx57+/Cre

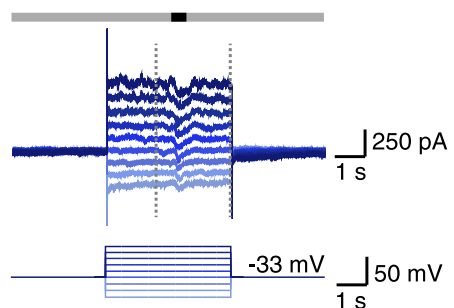

tained when comparing peak conductances (data not shown). In summary, tOFF- $\alpha$ RGCs received less excitatory synaptic input when horizontal cells were not excited by photoreceptors.

Together, we conclude that eliminating horizontal cell input (1) attenuated the light-driven spike rates of tOFF$\alpha$ RGCs because excitatory input from bipolar cells was decreased, (2) reduced the dynamic range of ganglion cell responses to contrast and temporal changes, and (3) affected spatial receptive field organization.

\section{Discussion}

Evidence has accumulated that horizontal cells of the mouse use three different mechanisms to feed signals back to photoreceptors. These mechanisms include proton- and hemichannel-mediated (ephaptic) feedback (Kemmler et al., 2014), and vesicular GABA release (Herrmann et al., 2011; Hirano et al., 2016). To study the functional role of horizontal cells for ganglion cell tuning, we aimed to arrest all feedback mechanisms simultaneously, without affecting the downstream circuitry. However, pharmacological blockade of feedback targets only one mechanism and has side effects, e.g., GABA blockers affect inner retina circuits. Here, we generated a new mouse line in which we deleted GluA2 and GluA4 specifically from horizontal cells. In this line, horizontal cells were completely deprived of glutamatergic, light-dependent input from photoreceptors. Consequently, horizontal cell output is presumed to be static and no longer modulated by light. As no obvious changes in retinal morphology occurred, this mouse line presented an ideal tool to study the impact of horizontal cells for visual processing without pharmacological intervention. Light response recordings revealed that tOFF- $\alpha$ RGCs received less excitatory input from bipolar cells when horizontal cells lacked glutamatergic input. In consequence, tOFF- $\alpha$ RGCs showed strongly decreased spike rates and were not able to respond to high temporal frequencies or low contrasts, revealing a compressed

$8 a)$. From these responses, we calculated the excitatory and inhibitory conductances.

In controls, the excitatory conductance increased after the onset of the dark flash whereas the inhibitory conductance decreased, revealing a substantial tonic inhibitory input from amacrine cells as reported before (Van Wyk et al., 2009). In cells from retinas with GluA2/4-deficient horizontal cells, excitatory conductances were significantly smaller compared with controls (Fig. $8 b, c$; measured as the integral during the stimulus). This was true for all spot sizes (for all spot sizes: $p<0.023$, Wilcoxon rank sum test). Inhibitory conductances in GluA2/4-deficient retinas were not significantly reduced (Fig. $8 b, c ; p>0.1806$, Wilcoxon rank sum test). Similar results as for response integrals were ob- dynamic range. Moreover, tOFF- $\alpha$ RGCs showed altered surrounds. Our findings thus suggest that horizontal cells are, at least for this type of ganglion cell, important for gain control at the photoreceptor synapse and affect center/surround organization of receptive fields.

Mangel (1991) showed that injecting hyperpolarizing currents into horizontal cells increased the firing rate of OFF-center ganglion cells in the rabbit retina. Surprisingly, eliminating glutamatergic input to and consequently arresting feedback from horizontal cells reduced spike rates and compressed the dynamic range in tOFF- $\alpha$ RGCs. The reason may be that signal transmission from photoreceptors to OFF bipolar cells was decreased, resulting in reduced excitatory input at the ganglion cell level. But 
why was signal transmission impaired in the outer retina? In the mouse retina, hemichannel-mediated feedback from horizontal cells defines the basal calcium level in cone terminals (Kemmler et al., 2014) and thereby adjusts synaptic gain. Specifically, in contrast to fish retina, when hemichannels are activated by horizontal cell hyperpolarization, presynaptic calcium levels are decreased, resulting in smaller cone responses. In GluA2/4 fl/ fl:Cx57+/Cre mice, horizontal cells are presumably hyperpolarized (Fig. 3e). Thus, we hypothesize that hemichannels are constantly activated, resulting in decreased cone responses. This may lead to reduced excitatory input from bipolar to ganglion cells in this mouse line.

Moreover, it was shown for the mouse that proton-mediated feedback amplifies light responses to low contrast and attenuates light responses to high contrast (Kemmler et al., 2014). Thus, rendering pH-mediated feedback static (i.e., independent from light) could also contribute to the decreased dynamic range in the contrast tuning of ganglion cells (cells failed to respond to low contrasts). The same mechanisms may also contribute to the shift in temporal tuning toward lower temporal frequencies in GluA2/4deficient mice. This is also in line with an earlier report that showed temporal tuning of parasol cells (equivalent to $\alpha$ RGCs in the mouse; Peichl, 1991) to be largely governed by the excitatory bipolar cell output (Crook et al., 2014).

Horizontal cells can affect surrounds by modulating photoreceptor output (see above) and providing GABAergic input to bipolar cells, which leads to depolarizing or hyperpolarizing effects (depending on intracellular chloride concentrations; Duebel et al., 2006). Horizontal cells that lack GluA2 and GluA4 are presumably arrested in a hyperpolarized state. This decreases GABA release and thereby reduces the antagonizing effect for OFF bipolar cells. Consistently, tOFF- $\alpha$ RGCs lacked surrounds in GluA2/4-deficient mice, in line with earlier reports on horizontal cell contribution to center/surround antagonism in mouse (Chaya et al., 2017) and primate ganglion cells (Davenport et al., 2008; Crook et al., 2014).

Earlier studies have emphasized the role of amacrine cells for the center/surround organization of ganglion cell receptive fields in nonprimate mammals (Zaghloul et al., 2007; Dedek et al., 2008; Eggers and Lukasiewicz, 2010; Marco et al., 2013; Purgert and Lukasiewicz, 2015). The altered surround suppression of ganglion cell responses while stimulating the retina with large black spots may reflect the contribution of amacrine cells. As mentioned above, it is highly unlikely that horizontal cells are still capable of mediating spatially organized feedback in GluA2/4deficient mice in a light-dependent manner. Therefore, amacrine cell feedback is thought to be the sole source of surround inhibition. Pink noise stimulation did not reveal this phenomenon; ganglion cell surrounds were largely abolished. In sharp opposition to large black spots, pink noise is low in contrast across a large spatial scale and modulated locally on a small spatial scale, which may not be sufficient to fully reveal the impact of widefield amacrine cells on ganglion cell receptive fields. The differ- ences in the stimulus properties may therefore help to explain the observed differences in the center-surround structures of tOFF$\alpha$ RGCs in GluA2/4-deficient mice.

The spatially larger center responses we see in GluA2/4deficient retinas could in principle also arise from an altered anatomical organization of cells in the inner retina. We consider this as unlikely because (1) qualitative morphological changes of neurobiotin-injected of tOFF- $\alpha$ RGCs have not been obvious (data not shown) and (2) the nearest-neighbor distances obtained from the mosaics of tOFF- $\alpha$ RGCs in MEA recordings did not differ between genotypes (GluA2/4 fl/fl: $138.4 \pm 4.6 \mu \mathrm{m}$; GluA2/4 fl/fl:Cx57-Cre: $139.3 \pm 10.6 \mu \mathrm{m}$; for three pairs of agematched littermates: $p=1$, Wilcoxon signed rank test).

To validate the GluA2/4 fl/fl:Cx57+/Cre mouse line, we controlled for (1) the specificity of the Cre expression, (2) successful deletion of GluA2 and GluA4, (3) morphological changes in the outer retina, and (4) residual glutamate-induced currents in horizontal cells. As described earlier (Sonntag et al., 2012; Ströh et al., 2013; Hirano et al., 2016; Chaya et al., 2017), the Cx57 promoter is highly specific for horizontal cells: Cre recombinase was exclusively expressed in this cell type. Cre recombinase activity deleted GluA2 and GluA4 AMPA receptor subunits from horizontal cells. Consistently, GluA2/3 and GluA4 immunoreactivities were strongly reduced in the outer but unchanged in the inner plexiform layer. Glutamate-induced inward currents of horizontal cells were completely eliminated, indicating that mouse horizontal cells only express GluA2 and GluA4; a combination unusual for interneurons (Geiger et al., 1995).

We additionally analyzed whether triad synapses, formed by photoreceptors, ON bipolar and horizontal cell dendrites, showed obvious changes. However, triad synapses and the number of bassoon-labeled ribbons showed no obvious alterations in GluA2/4-deficient mice, suggesting that this synaptic complex is formed and maintained even when one cell type is deprived of its excitatory input. The integrity of the synapse was also examined 
by labeling for postsynaptic complexes, GluK1 (OFF bipolar) and Cav1.1 (crossreacting with GPR179 and labeling the mGluR6 complex). Again, we did not find any significant differences between controls and GluA2/4-deficient animals.

However, we cannot completely rule out that glutamate receptor deletion alters the development of the outer retina, which could have contributed to the effects seen in downstream neurons. For example, disruption of TRPM1 on ON bipolar cells results in a decreased number of synaptic connections with amacrine cells (Kozuka et al., 2017). Similarly, it was shown that GABA release onto bipolar cell terminals is necessary for maintaining axonal GABA receptors (Schubert et al., 2013). However, when the vesicular GABA transporter is deleted from horizontal cells, the number of GABA receptors on bipolar cell dendrites and terminals is unaffected (Hoon et al., 2015). This indicates that at least altered GABAergic feedback in GluA2/4-deficient horizontal cells may not have caused alterations in downstream neurons.

We also tested whether the lack of one allele of $C x 57$, presumably reducing horizontal cell coupling, had itself an effect on ganglion cell tuning. We analyzed GluA4 fl/fl: $\mathrm{Cx} 57+/ \mathrm{Cre}$ mice in which glutamate-induced currents in horizontal cells were reduced by 75\% (Ströh et al., 2013). We detected no significant changes in responses to frequency or contrast changes in tOFF$\alpha$ RGCs (Fig. 9). Thus, the reduced input from photoreceptors (25\% remaining; Ströh et al., 2013) is sufficient for normal visual processing and the lack of one $C \times 57$ allele cannot account for the changes that were observed in GluA2/4-deficient mice. In a previous study, we discovered that deletion of both alleles of Cx57 abolished dye coupling of horizontal cells but did not change the spatial tuning of ganglion cells (Dedek et al., 2008). Whether deletion of GluAs could increase coupling is hard to predict as we do not yet know the role of glutamate receptors in the signaling pathways that regulate the coupling of mouse horizontal cells.

Similar to the highly complex nature of signaling mechanisms from horizontal cells to postsynaptic targets, the data presented here suggest that the functional role of this feedback for the retinal output signals is equally complex. Our insights emphasize the impact of horizontal cells on at least two features of visual processing: on the dynamic range of ganglion cells, and on the receptive field organization in postsynaptic neurons. If these conclusions, drawn from the analysis of tOFF- $\alpha$ RGCs, can be carried over to other ganglion cell types remains a challenge for future studies.

\section{References}

Baden T, Berens P, Franke K, Román Rosón M, Bethge M, Euler T (2016) The functional diversity of retinal ganglion cells in the mouse. Nature 529:345-350. CrossRef Medline

Bleckert A, Schwartz GW, Turner MH, Rieke F, Wong RO (2014) Visual space is represented by nonmatching topographies of distinct mouse retinal ganglion cell types. Curr Biol 24:310-315. CrossRef Medline

Chaya T, Matsumoto A, Sugita Y, Watanabe S, Kuwahara R, Tachibana M, Furukawa T (2017) Versatile functional roles of horizontal cells in the retinal circuit. Sci Rep 7:5540. CrossRef Medline

Conover WJ, Iman RL (1981) Rank transformations as a bridge between parametric and nonparametric statistics. Am Stat 35:124-129. CrossRef

Crook JD, Packer OS, Dacey DM (2014) A synaptic signature for ON- and OFF-center parasol ganglion cells of the primate retina. Vis Neurosci 31:57-84. CrossRef Medline

Davenport CM, Detwiler PB, Dacey DM (2008) Effects of pH buffering on horizontal and ganglion cell light responses in primate retina: evidence for the proton hypothesis of surround formation. J Neurosci 28:456-464. CrossRef Medline

Dedek K, Pandarinath C, Alam NM, Wellershaus K, Schubert T, Willecke K, Prusky GT, Weiler R, Nirenberg S (2008) Ganglion cell adaptability: does the coupling of horizontal cells play a role? PLoS One 3:e1714. CrossRef Medline

Dorgau B, Herrling R, Schultz K, Greb H, Segelken J, Ströh S, Bolte P, Weiler R, Dedek K, Janssen-Bienhold U (2015) Connexin50 couples axon terminals of mouse horizontal cells by homotypic gap junctions. J Comp Neurol 523:2062-2081. CrossRef Medline

Duebel J, Haverkamp S, Schleich W, Feng G, Augustine GJ, Kuner T, Euler T (2006) Two-photon imaging reveals somatodendritic chloride gradient in retinal ON-type bipolar cells expressing the biosensor clomeleon. Neuron 49:81-94. CrossRef Medline

Eggers ED, Lukasiewicz PD (2010) Interneuron circuits tune inhibition in retinal bipolar cells. J Neurophysiol 103:25-37. CrossRef

Elstrott J, Anishchenko A, Greschner M, Sher A, Litke AM, Chichilnisky EJ, Feller MB (2008) Direction selectivity in the retina is established independent of visual experience and cholinergic retinal waves. Neuron 58: 499-506. CrossRef Medline

Euler T, Hausselt SE, Margolis DJ, Breuninger T, Castell X, Detwiler PB, Denk W (2009) Eyecup scope: optical recordings of light stimulus-evoked fluorescence signals in the retina. Pflugers Arch 457:1393-1414. CrossRef Medline

Fahey PK, Burkhardt DA (2003) Center-surround organization in bipolar cells: symmetry for opposing contrasts. Vis Neurosci 20:1-10. CrossRef Medline

Feigenspan A, Babai N (2015) Functional properties of spontaneous excitatory currents and encoding of light/dark transitions in horizontal cells of the mouse retina. Eur J Neurosci 42:2615-2632. CrossRef Medline

Field GD, Sher A, Gauthier JL, Greschner M, Shlens J, Litke AM, Chichilnisky EJ (2007) Spatial properties and functional organization of small bistratified ganglion cells in primate retina. J Neurosci 27:13261-13272. CrossRef Medline

Franke K, Berens P, Schubert T, Bethge M, Euler T, Baden T (2017) Inhibition decorrelates visual feature representations in the inner retina. Nature 542:439-444. CrossRef Medline

Fuchs EC, Zivkovic AR, Cunningham MO, Middleton S, Lebeau FE, Bannerman DM, Rozov A, Whittington MA, Traub RD, Rawlins JN, Monyer H (2007) Recruitment of parvalbumin-positive interneurons determines hippocampal function and associated behavior. Neuron 53:591-604. CrossRef Medline

Geiger JR, Melcher T, Koh DS, Sakmann B, Seeburg PH, Jonas P, Monyer H (1995) Relative abundance of subunit mRNAs determines gating and $\mathrm{Ca}^{2+}$ permeability of AMPA receptors in principal neurons and interneurons in rat CNS. Neuron 15:193-204. CrossRef Medline

Hack I, Frech M, Dick O, Peichl L, Brandstätter JH (2001) Heterogeneous distribution of AMPA glutamate receptor subunits at the photoreceptor synapses of rodent retina. Eur J Neurosci 13:15-24. CrossRef Medline

Hasan N, Ray TA, Gregg RG (2016) CACNA1S expression in mouse retina: novel isoforms and antibody cross-reactivity with GPR179. Vis Neurosci 33:E009. CrossRef Medline

Haverkamp S, Grünert U, Wässle H (2000) The cone pedicle, a complex synapse in the retina. Neuron 27:85-95. CrossRef Medline

Herrmann R, Heflin SJ, Hammond T, Lee B, Wang J, Gainetdinov RR, Caron MG, Eggers ED, Frishman LJ, McCall MA, Arshavsky VY (2011) Rod vision is controlled by dopamine-dependent sensitization of rod bipolar cells by GABA. Neuron 72:101-110. CrossRef Medline

Hirano AA, Liu X, Boulter J, Grove J, Pérez de Sevilla Müller L, Barnes S, Brecha NC (2016) Targeted deletion of vesicular GABA transporter from retinal horizontal cells eliminates feedback modulation of photoreceptor calcium channels. eNeuro 3:ENEURO.0148-15.2016. CrossRef Medline

Hirasawa H, Kaneko A (2003) pH changes in the invaginating synaptic cleft mediate feedback from horizontal cells to cone photoreceptors by modulating $\mathrm{Ca}^{2+}$ channels. J Gen Physiol 122:657-671. CrossRef Medline

Hombach S, Janssen-Bienhold U, Söhl G, Schubert T, Büssow H, Ott T, Weiler R, Willecke K (2004) Functional expression of connexin57 in horizontal cells of the mouse retina. Eur J Neurosci 19:2633-2640. CrossRef Medline

Hoon M, Sinha R, Okawa H, Suzuki SC, Hirano AA, Brecha N, Rieke F, Wong RO (2015) Neurotransmission plays contrasting roles in the maturation of inhibitory synapses on axons and dendrites of retinal bipolar cells. Proc Natl Acad Sci U S A 112:12840-12845. CrossRef Medline

Jackman SL, Babai N, Chambers JJ, Thoreson WB, Kramer RH (2011) A 
positive feedback synapse from retinal horizontal cells to cone photoreceptors. PLoS Biol 9:e1001057. CrossRef Medline

Janssen-Bienhold U, Trümpler J, Hilgen G, Schultz K, Pérez de Sevilla Müller LP, Sonntag S, Dedek K, Dirks P, Willecke K, Weiler R (2009) Connexin57 is expressed in dendro-dendritic and axo-axonal gap junctions of mouse horizontal cells and its distribution is modulated by light. J Comp Neurol 513:363-374. CrossRef Medline

Kamermans M, Fahrenfort I (2004) Ephaptic interactions within a chemical synapse: hemichannel-mediated ephaptic inhibition in the retina. Curr Opin Neurobiol 14:531-541. CrossRef Medline

Kamermans M, Fahrenfort I, Schultz K, Janssen-Bienhold U, Sjoerdsma T, Weiler R (2001) Hemichannel-mediated inhibition in the outer retina. Science 292:1178-1180. CrossRef Medline

Kemmler R, Schultz K, Dedek K, Euler T, Schubert T (2014) Differential regulation of cone calcium signals by different horizontal cell feedback mechanisms in the mouse retina. J Neurosci 34:11826-11843. CrossRef Medline

Knop GC, Feigenspan A, Weiler R, Dedek K (2011) Inputs underlying the ON-OFF light responses of type 2 wide-field amacrine cells in TH::GFP mice. J Neurosci 31:4780-4791. CrossRef Medline

Kozuka T, Chaya T, Tamalu F, Shimada M, Fujimaki-Aoba K, Kuwahara R, Watanabe SI, Furukawa T (2017) The TRPM1 channel is required for development of the rod ON bipolar cell-AII amacrine cell pathway in the retinal circuit. J Neurosci 37:9889-9900. CrossRef Medline

Krieger B, Qiao M, Rousso DL, Sanes JR, Meister M (2017) Four alpha ganglion cell types in mouse retina: function, structure, and molecular signatures. PLoS One 12:e0180091. CrossRef Medline

Kuffler SW (1953) Discharge patterns and functional organization of mammalian retina. J Neurophysiol 16:37-68. CrossRef Medline

Lyubarsky AL, Falsini B, Pennesi ME, Valentini P, Pugh EN Jr (1999) UVand midwave-sensitive cone-driven retinal responses of the mouse: a possible phenotype for coexpression of cone photopigments. J Neurosci 19: 442-455. Medline

Lyubarsky AL, Daniele LL, Pugh EN Jr (2004) From candelas to photoisomerizations in the mouse eye by rhodopsin bleaching in situ and the light-rearing dependence of the major components of the mouse ERG. Vision Res 44:3235-3251. CrossRef Medline

Mangel SC (1991) Analysis of the horizontal cell contribution to the receptive field surround of ganglion cells in the rabbit retina. J Physiol Lond 442:211-234. CrossRef Medline

Manookin MB, Beaudoin DL, Ernst ZR, Flagel LJ, Demb JB (2008) Disinhibition combines with excitation to extend the operating range of the OFF visual pathway in daylight. J Neurosci 28:4136-4150. CrossRef Medline

Marco SD, Protti DA, Solomon SG (2013) Excitatory and inhibitory contributions to receptive fields of alpha-like retinal ganglion cells in mouse. J Neurophysiol 110:1426-1440. CrossRef Medline

Pandarinath C, Bomash I, Victor JD, Prusky GT, Tschetter WW, Nirenberg S (2010) A novel mechanism for switching a neural system from one state to another. Front Comput Neurosci 4:2. CrossRef Medline

Pang JJ, Gao F, Wu SM (2003) Light-evoked excitatory and inhibitory synaptic inputs to ON and OFF alpha ganglion cells in the mouse retina. J Neurosci 23:6063-6073. Medline

Peichl L (1991) Alpha ganglion cells in mammalian retinae: common properties, species differences, and some comments on other ganglion cells. Vis Neurosci 7:155-169. CrossRef Medline

Peichl L, González-Soriano J (1994) Morphological types of horizontal cell in rodent retinae: a comparison of rat, mouse, gerbil, and guinea pig. Vis Neurosci 11:501-517. CrossRef Medline

Purgert RJ, Lukasiewicz PD (2015) Differential encoding of spatial information among retinal on cone bipolar cells. J Neurophysiol 114:1757-1772. CrossRef
Schindelin J, Arganda-Carreras I, Frise E, Kaynig V, Longair M, Pietzsch T, Preibisch S, Rueden C, Saalfeld S, Schmid B, Tinevez JY, White DJ, Hartenstein V, Eliceiri K, Tomancak P, Cardona A (2012) Fiji: an opensource platform for biological-image analysis. Nat Methods 9:676-682. CrossRef Medline

Schubert T, Hoon M, Euler T, Lukasiewicz PD, Wong RO (2013) Developmental regulation and activity-dependent maintenance of GABAergic presynaptic inhibition onto rod bipolar cell axonal terminals. Neuron 78:124-137. CrossRef Medline

Shimshek DR, Bus T, Grinevich V, Single FN, Mack V, Sprengel R, Spergel DJ, Seeburg PH (2006) Impaired reproductive behavior by lack of GluR-B containing AMPA receptors but not of NMDA receptors in hypothalamic and septal neurons. Mol Endocrinol 20:219-231. CrossRef Medline

Sinclair JR, Jacobs AL, Nirenberg S (2004) Selective ablation of a class of amacrine cells alters spatial processing in the retina. J Neurosci 24:14591467. CrossRef Medline

Sonntag S, Dedek K, Dorgau B, Schultz K, Schmidt KF, Cimiotti K, Weiler R, Löwel S, Willecke K, Janssen-Bienhold U (2012) Ablation of retinal horizontal cells from adult mice leads to rod degeneration and remodeling in the outer retina. J Neurosci 32:10713-10724. CrossRef Medline

Ströh S, Sonntag S, Janssen-Bienhold U, Schultz K, Cimiotti K, Weiler R, Willecke K, Dedek K (2013) Cell-specific cre recombinase expression allows selective ablation of glutamate receptors from mouse horizontal cells. PloS One 8:e83076. CrossRef Medline

Taylor WR (1999) TTX attenuates surround inhibition in rabbit retinal ganglion cells. Vis Neurosci 16:285-290. Medline

Taylor WR, Vaney DI (2002) Diverse synaptic mechanisms generate direction selectivity in the rabbit retina. J Neurosci 22:7712-7720. Medline

Thoreson WB, Mangel SC (2012) Lateral interactions in the outer retina. Prog Retin Eye Res 31:407-441. CrossRef Medline

Thoreson WB (2007) Kinetics of synaptic transmission at ribbon synapses of rods and cones. Mol Neurobiol 36:205-223. CrossRef Medline

Thoreson WB, Babai N, Bartoletti TM (2008) Feedback from horizontal cells to rod photoreceptors in vertebrate retina. J Neurosci 28:5691-5695. CrossRef Medline

Tykocinski LO, Sinemus A, Rezavandy E, Weiland Y, Baddeley D, Cremer C, Sonntag S, Willecke K, Derbinski J, Kyewski B (2010) Epigenetic regulation of promiscuous gene expression in thymic medullary epithelial cells. Proc Natl Acad Sci U S A 107:19426-19431. CrossRef Medline

Van Wyk M, Wässle H, Taylor WR (2009) Receptive field properties of ONand OFF-ganglion cells in the mouse retina. Vis Neurosci 26:297-308. CrossRef Medline

VanLeeuwen M, Fahrenfort I, Sjoerdsma T, Numan R, Kamermans M (2009) Lateral gain control in the outer retina leads to potentiation of center responses of retinal neurons. J Neurosci 29:6358-6366. CrossRef Medline

Verweij J, Kamermans M, Spekreijse H (1996) Horizontal cells feed back to cones by shifting the cone calcium-current activation range. Vision Res 36:3943-3953. CrossRef Medline

Wu SM (1991) Input-output relations of the feedback synapse between horizontal cells and cones in the tiger salamander retina. J Neurophysiol 65:1197-1206. CrossRef Medline

Wu SM (1992) Feedback connections and operation of the outer plexiform layer of the retina. Curr Opin Neurobiol 2:462-468. CrossRef Medline

Yang XL, Wu SM (1991) Feedforward lateral inhibition in retinal bipolar cells: input-output relation of the horizontal cell-depolarizing bipolar cell synapse. Proc Natl Acad Sci U S A 88:3310-3313. CrossRef Medline

Zaghloul KA, Manookin MB, Borghuis BG, Boahen K, Demb JB (2007) Functional circuitry for peripheral suppression in mammalian Y-type retinal ganglion cells. J Neurophysiol 97:4327-4340. CrossRef Medline 